Article

\title{
The Major Capsid Protein, VP1, of the Mouse Polyomavirus Stimulates the Activity of Tubulin Acetyltransferase 1 by Microtubule Stabilization
}

\author{
Lenka Horníková ${ }^{1} \mathbb{D}$, Kateřina Bruštíková ${ }^{1}$, Boris Ryabchenko ${ }^{1}$, Ilia Zhernov ${ }^{2,3}{ }^{10}$, \\ Martin Fraiberk ${ }^{1}$, Zuzana Mariničová ${ }^{1,+, \ddagger}$, Zdeněk Lánský $^{2}\left(\mathbb{D}\right.$ and Jitka Forstová ${ }^{1, *}$ \\ 1 Department of Genetics and Microbiology, Faculty of Science, Charles University, BIOCEV, 25250 Vestec, \\ Czech Republic; horniko1@natur.cuni.cz (L.H.); katerina.podolska@natur.cuni.cz (K.B.); \\ boris.ryabchenko@natur.cuni.cz (B.R.); martin.fraiberk@natur.cuni.cz (M.F.); \\ zuzana.marinicova@tu-dresden.de (Z.M.) \\ 2 Institute of Biotechnology of the Czech Academy of Sciences, BIOCEV, 25250 Vestec, Czech Republic; \\ Ilia.Zhernov@ibt.cas.cz (I.Z.); zdenek.lansky@ibt.cas.cz (Z.L.) \\ 3 Faculty of Mathematics and Physics, Charles University, 12844 Prague, Czech Republic \\ * Correspondence: jitkaf@natur.cuni.cz; Tel.: +42-022-195-1730 \\ † Current address: Paul Langerhans Institute Dresden of the Helmholtz Center Munich at University Hospital \\ and Faculty of Medicine, Technische Universität Dresden, 01307 Dresden, Germany. \\ $\ddagger$ Current address: German Center for Diabetes Research (DZD e.V.), 85764 Neuherberg, Germany.
}

Received: 22 January 2020; Accepted: 14 February 2020; Published: 18 February 2020

check for updates

\begin{abstract}
Viruses have evolved mechanisms to manipulate microtubules (MTs) for the efficient realization of their replication programs. Studying the mechanisms of replication of mouse polyomavirus (MPyV), we observed previously that in the late phase of infection, a considerable amount of the main structural protein, VP1, remains in the cytoplasm associated with hyperacetylated microtubules. VP1-microtubule interactions resulted in blocking the cell cycle in the G2/M phase. We are interested in the mechanism leading to microtubule hyperacetylation and stabilization and the roles of tubulin acetyltransferase 1 ( $\alpha$ TAT1) and deacetylase histone deacetylase 6 (HDAC6) and VP1 in this mechanism. Therefore, HDAC6 inhibition assays, $\alpha$ TAT1 knock out cell infections, in situ cell fractionation, and confocal and TIRF microscopy were used. The experiments revealed that the direct interaction of isolated microtubules and VP1 results in MT stabilization and a restriction of their dynamics. VP1 leads to an increase in polymerized tubulin in cells, thus favoring $\alpha$ TAT1 activity. The acetylation status of MTs did not affect MPyV infection. However, the stabilization of MTs by VP1 in the late phase of infection may compensate for the previously described cytoskeleton destabilization by MPyV early gene products and is important for the observed inhibition of the $\mathrm{G} 2 \rightarrow \mathrm{M}$ transition of infected cells to prolong the $\mathrm{S}$ phase.
\end{abstract}

Keywords: mouse polyomavirus; VP1; microtubules; $\alpha$-tubulin acetyltransferase 1 ; histone deacetylase 6; microtubule acetylation; microtubule stabilization

\section{Introduction}

The mouse polyomavirus (MPyV) belongs to the Polyomaviridae family, a group of non-enveloped, tumorigenic viruses. The virus's genome is arranged in one molecule of circular dsDNA associated with histones (except histone H1) and encodes six gene products, three early antigens (large, middle and small $\mathrm{T}$ ) and three structural proteins (the major capsid protein, VP1, and the minor capsid proteins, VP2 and VP3). VP2 is a longer variant of VP3 with a unique prolonged N-terminus. Early antigens are essential for productive virus replication. They participate in viral transcription and 
DNA replication and deregulate infected cells to ensure a suitable environment for the progression of a virus's replicative cycle.

The protein capsid with icosahedral symmetry is composed of 72 capsomeres. Each capsomere is built of molecules of VP1 arranged into pentamers, and each pentamer is associated with one molecule of either the VP2 or VP3 minor protein [1]. The minor proteins are not exposed on the surface of the capsid shell. Capsomeres are formed immediately after their synthesis in the cytoplasm, and the complex is transported into the nucleus, where the assembly of virions takes place. Although each structural protein possesses its own nuclear localization signal (NLS), individual expression leads to predominantly cytoplasmic localization. For the successful transport of structural proteins into the nucleus, the capsomere conformation and cooperation of the NLS of the major and the minor structural proteins are absolutely essential [2,3]. The VP1 protein has the ability to self-assemble into capsid-like structures known as virus-like particles (VLPs). Neither minor proteins nor VP1 posttranslational modifications of the VP1 protein are needed for the formation of VLPs [4].

A great deal is known about the interaction of VP1 with the MPyV ganglioside receptor during the virus's entry and genome delivery to the cell nucleus [5]. However, interactions of VP1 with cellular structures and their significance to infection are not well characterized. Several cellular proteins have been described to interact with VP1 during infection. VP1 interacts with importins, which mediate not only the nuclear transport of capsid proteins during virion assembly but also ensure the translocation of the viral genome from the cytoplasm to the nucleus during the early stages of virus infection $[2,6]$. In the nucleus, VP1 interacts with the multifunctional cellular transcription factor YY1 [7] and poly(ADP-ribose) polymerase 1 (PARP-1) [8]. It has been suggested that these proteins may be involved in viral transcription and replication regulation and also in viral uncoating and morphogenesis [8,9]. The cellular chaperone, heat shock cognate protein 70 (Hsc70), interacts with VP1 in the cytoplasm immediately after VP1 synthesis and translocates with capsomeres into the nucleus. It was proposed that VP1-Hsc70 interaction prevents the formation of empty capsids in the cytoplasm [10]. The presence of VP1 in cells also affects the posttranslational modification of $\alpha$-tubulin, namely its acetylation with lysine $40(\alpha \mathrm{K} 40)$ [3]. This modification is localized in the hollow lumen of the microtubules [11] and ensures the resistance of the microtubules to mechanical damage [12-14]. Thus, $\alpha \mathrm{K} 40$ is a marker of stable microtubules. The primary enzyme responsible for $\alpha \mathrm{K} 40$ acetylation is $\alpha$-tubulin acetyltransferase 1 ( $\alpha$ TAT1) [15-17]. This enzyme preferentially acetylates polymerized microtubules over tubulin dimers [17]. Deacetylation is maintained by histone deacetylase 6 (HDAC6) [18], which prefers tubulin dimers as a substrate [19].

In our previous study [3], we identified microtubules (including the mitotic spindle) and the cellular chaperone heat shock protein 90 (Hsp90) as other VP1-interacting partners. During the late phase of infection, VP1 can be seen in the cytoplasm decorating microtubules. Complexes of VP1 and microtubules are highly insoluble during in vitro fractionation. We showed that dynein was not responsible for the VP1-microtubule association, and, although Hsp90 could be found in VP1-microtubule complexes, it did not mediate the interaction between VP1 and the microtubules. Nevertheless, the mechanism of VP1-microtubule formation remains obscure. We also observed microtubule hyperacetylation in MPyV infected cells and in cells producing VP1 only.

MPyV gene products affect the cell cycle. Cells infected by MPyV pass through at least two cell cycles [20], but they exhibit a prolonged S phase and no G2 $\rightarrow$ M transition [21]. Dahl et al. [21] showed that cell cycle arrest is connected with the replication of viral DNA, which activates the ATM (protein kinase ataxia telangiectasia mutated) pathway, leading to the inactivation of CDK1 and thus induces cell cycle arrest. We found that the interaction of VP1 with microtubule structures in the cytoplasm resulted in a cell cycle block in the G2/M phase [3]. While early antigens are apparently involved in the first cell cycle block, VP1 may contribute to blocking the second cell cycle, thus enabling the completion of the virus assembly.

In this study, we focus on understanding the relationship of VP1-microtubule binding, microtubule stabilization, and tubulin $\alpha \mathrm{K} 40$ acetylation. In addition, we study the relevance of $\alpha \mathrm{K} 40$ acetylation for 
$\mathrm{MPyV}$ infection. We revealed that, despite increasing levels of microtubule acetylation in the late phase of MPyV infection, the levels of HDAC6 and $\alpha$ TAT1 expression were not affected. We further showed, during in vitro experiments, that VP1 interacts with microtubules directly and increases their stability. The stabilization of microtubules by VP1 was also proven in VP1-producing cells. Based on our results, we propose that VP1 binding to microtubules leads to microtubule stabilization, which increases the amount of $\alpha$ TAT1 substrate and stimulates $\alpha$ TAT1 activity. Thus, the hyperacetylation of microtubules seems to be a consequence of their stabilization mediated by VP1. However, the microtubule acetylation status per se had no significant effect on MPyV infection.

\section{Materials and Methods}

\subsection{Cells and Viruses}

3T6 (ATCC; CCL-96) mouse fibroblasts and WOP cells [22] (mouse fibroblasts that constitutively produce large $\mathrm{T}$ antigens of the mouse polyomavirus) were grown at $37^{\circ} \mathrm{C}$ in a $5 \% \mathrm{CO}_{2}$-air humidified incubator using Dulbecco's modified Eagle's medium (DMEM; Sigma-Aldrich, Saint Louis, MO, USA) supplemented with 10\% bovine serum (Thermo Fisher Scientific, Waltham, MA, USA) and 2 mM glutamine (Thermo Fisher Scientific). TAT KO cells [23], mouse fibroblasts with $\alpha$ TAT knock out, and their wild-type counterparts, 3T3-wt cells, were grown at $37^{\circ} \mathrm{C}$ in a $5 \% \mathrm{CO}_{2}$-air humidified incubator using DMEM (Sigma-Aldrich) supplemented with 10\% bovine serum (Thermo Fisher Scientific), 2 mM glutamine (Thermo Fisher Scientific), 1\% non-essential amino acids (Sigma-Aldrich), and $5 \mathrm{mM}$ $\beta$-mercaptoethanol (Sigma-Aldrich). SF9 (Spodoptera frugiperda) insect cells (ATCC; CRL-1711) were cultivated as adherent cultures at $27^{\circ} \mathrm{C}$ in a TNM-FH medium (Sigma-Aldrich) containing $10 \%$ bovine serum (Thermo Fisher Scientific) supplemented with $4 \mathrm{mM}$ L-glutamine (Thermo Fisher Scientific). For the stable expression of $\alpha$ TAT1 fused with enhanced green fluorescent protein (EGFP), WOP cells were transfected with pEGFP- $\alpha$ TAT. The WOP-EGFP- $\alpha$ TAT1 cell line was established by sub-cloning and maintained upon blasticidin (InvivoGen, San Diego, CA, USA) selection antibiotics in a DMEM culture medium supplemented with 10\% bovine serum (Thermo Fisher Scientific) and $2 \mathrm{mM}$ glutamine (Thermo Fisher Scientific). Mouse polyomavirus (BG strain) was isolated and purified from infected 3 T6 cells using the standard protocol [24]. Recombinant baculovirus AcDB3/VP1/EGFP-t-VP3 [25] was propagated using the standard protocol. For infection, the cells were incubated for $1 \mathrm{~h}(\mathrm{~h})$ with a virus inoculum under a multiplicity of infection (MOI) with 10 plaque forming units per cell.

\subsection{Plasmids}

For the expression of VP1, the plasmids pwP (a gift from Christopher Buck; Addgene plasmid \#22519, Addgene, Cambridge, MA, USA) [26] and pVP1 [27] were used. As a control vector, the plasmid pCont [3] was used. The plasmid pEGFP- $\alpha$ TAT1 was constructed using the LR recombination of the donor plasmid pENTR- EGFP- $\alpha$ TAT1 and the destination vector pEF-DEST51 (Thermo Fisher Scientific) according to the manufacturer's protocol. The donor vector was constructed as follows. The sequence of $\alpha$ TAT1, fused at its N-terminus with EGFP, was amplified by PCR from plasmid pEF5B-FRT-GFP- $\alpha$ TAT1 (a gift from Maxence Nachury; Addgene plasmid \#27099) [17] using primer set 5' -CACCATGGTGAGCAAGGGCGAGGAG-3' and 5'-TTAGTATCGACTCTCCTCAGAG-3' and inserted into the donor vector pENTR/D-TOPO (Thermo Fisher Scientific) according to the manufacturer's protocol.

\subsection{Antibodies}

The primary antibodies used were the mouse monoclonal antibody for VP1 [28], rabbit polyclonal antibody for VP1 (prepared in our laboratory), rat monoclonal antibody for LT [29], mouse monoclonal antibody for $\alpha$-tubulin (Exbio, Prague, Czech Republic or Sigma-Aldrich), mouse monoclonal antibody for acetylated $\alpha$-tubulin (Sigma-Aldrich), mouse monoclonal antibody for $\beta$-tubulin (Sigma-Aldrich), goat polyclonal antibody for biotin (Sigma-Aldrich), rabbit polyclonal antibody for glyceraldehyde 
3-phosphate dehydrogenase (GAPDH; Sigma-Aldrich) and rabbit polyclonal antibody for GFP (Abcam, Cambridge, UK). The secondary antibodies used were goat anti-mouse and goat anti-rabbit antibodies conjugated with peroxidase (both from Bio-Rad, Hercules, CA, USA), the donkey anti-rat antibody conjugated with peroxidase (Santa Cruz Biotechnology, Dallas, TX, USA), the donkey anti-rabbit antibody conjugated with Alexa Fluor-488, the goat anti-mouse antibody conjugated with Cy3, the goat anti-rat antibody conjugated with Alexa Fluor-488 (all from Thermo Fisher Scientific), the goat anti-rabbit antibody conjugated with 5-nm gold particles and the goat anti-mouse antibody conjugated with 5-nm gold particles (both BBI Solutions, Cardiff, UK).

\subsection{Transfection of Cells}

The transfection of WOP or WOP-EGFP- $\alpha$ TAT1 cells was performed by electroporation in a Nucleofector ${ }^{\mathrm{TM}}$ device using Nucleofector V solution (Lonza, Basel, Switzerland) according to the manufacturer's instructions. Briefly, $4 \times 10^{6}$ exponentially growing cells were mixed with $6 \mu \mathrm{g}$ of plasmid DNA and $100 \mu \mathrm{L}$ of Nucleofector V solution and electroporated (program U-030).

\subsection{Quantitative Real-Time Polymerase Chain Reaction ( $q P C R$ )}

The total RNA from $5 \times 10^{5}$ cells was isolated using the High Pure RNA Isolation Kit (Roche) according to the manufacturer's protocol. Reverse transcription was carried out with the iScriptcDNA Synthesis Kit (Bio-Rad Laboratories) according to the producer's manual. cDNA was amplified by a polymerase chain reaction using the primer sets HDAC6 (transcription variant 1 a 2 ),

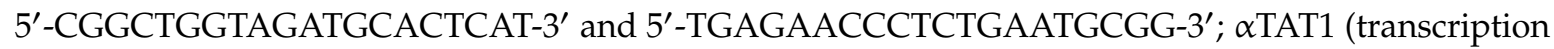

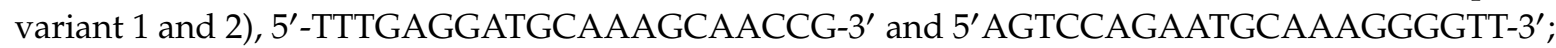
GAPDH, $5^{\prime}$-ATGACATCAAGAAGGTGGTG-3' and 5'-CATACCAGGAAATGAGCTTG- $3^{\prime}$. The quantification of the PCR products in real time was performed in a Light Cycler $480 \mathrm{II}$ from Roche using the Light Cycler 480 SYBR Green I Master Kit, according to the manufacturer's protocol. The quantification of target gene expression was performed using Light Cycler 480 II software based on the relative quantification method, thus determining the concentration of target amplicons normalized to the reference GAPDH gene. The fold change of RNA was compared with that of the mock-infected cells.

\subsection{In Situ Fractionation}

In situ fractionation was performed according to [30]. Cells grown on $3 \mathrm{~cm}$ Petri dishes were washed three times with a KM buffer (10 mM MES, $\mathrm{pH}=6.2 ; 10 \mathrm{mM} \mathrm{NaCl} ; 1.5 \mathrm{mM} \mathrm{MgCl} 2 ; 10 \%$ glycerol; a cocktail of protease inhibitors (Roche)). For the first extraction step, a KM buffer supplemented with $1 \%$ NP-40, 1 mM EGTA, and $5 \mathrm{mM}$ DTT was used. The buffer $(0.25 \mathrm{~mL})$ was then added to the dish, incubated for $3 \mathrm{~min}(\mathrm{~min})$ on ice, and removed. Another $0.5 \mathrm{~mL}$ of buffer was added to the dish, incubated for $27 \mathrm{~min}$ on ice, and then the extract was combined with the previous extract and marked as the NP-40 fraction. After the first extraction step, the structures on the dish were washed three times with a KM buffer and incubated with $0.25 \mathrm{~mL}$ of $\mathrm{KM}$ buffer supplemented with DNase I $\left(100 \mu / \mathrm{mL}\right.$; Roche) for $15 \mathrm{~min}$ at $37^{\circ} \mathrm{C}$. The extract was removed and marked as the DNase fraction. Structures on the dish were washed three times with a KM buffer and incubated for $30 \mathrm{~min}$ on ice in $0.25 \mathrm{~mL} \mathrm{KM}$ buffer containing $2 \mathrm{M} \mathrm{NaCl}, 1 \mathrm{mM}$ EGTA, and $5 \mathrm{mM}$ DTT. The extract was removed and marked as the $\mathrm{NaCl}$ fraction. After the third extraction step, the structures on the dish were washed three times with a $\mathrm{KM}$ buffer and incubated for $30 \mathrm{~min}$ at $37^{\circ} \mathrm{C}$ in $0.375 \mathrm{~mL}$ of $\mathrm{KM}$ buffer supplemented with DNase I (100 $\mu / \mathrm{mL}$; Roche) and RNase A (5 $\mu / \mathrm{mL}$; Serva Electrophoresis $\mathrm{GmbH}$, Heidelberg, Germany). The extract was removed and marked as the DNase/RNase fraction. After the final extraction step, the structures were washed three times with a KM buffer, and the remaining highly insoluble structures were dissolved in a KM buffer containing 1\% SDS and marked as the SDS fraction. Proteins in the extracted fractions were precipitated by acetone, dissolved in a Laemmli buffer, and analyzed by SDS electrophoresis. 


\subsection{Immunofluorescence Staining}

Cells grown on the coverslips were washed three times in phosphate-buffered saline (PBS; Lonza). Then, the samples were fixed with 3.7\% paraformaldehyde in PBS for $15 \mathrm{~min}$ and permeabilized in $0.5 \%$ Triton X-100 in PBS for $5 \mathrm{~min}$. After being washed in PBS ( $\times 10 \mathrm{~min})$, the samples were blocked with $0.25 \%$ gelatin and $0.25 \%$ bovine serum albumin in PBS for $30 \mathrm{~min}$. Immunostaining with primary and secondary antibodies was carried out for $1 \mathrm{~h}$ and $30 \mathrm{~min}$, respectively, with extensive washing in PBS after incubation. Then, the coverslips were briefly washed in deionized water, air dried, and mounted in DAPI Gold solution (Thermo Fisher Scientific). The samples were observed using an Olympus IX71 microscope or confocal microscope Zeiss LSM880.

\subsection{Western Blot Analysis}

The cells were harvested at the indicated times, washed with PBS, and resuspended in an ice-cold RIPA buffer (150 mM NaCl; 5 mM EDTA; $50 \mathrm{mM}$ Tris-HCl pH = 7.4; 0.05\% NP-40; 1\% sodium deoxycholate; $1 \%$ Triton X-100; $0.1 \%$ SDS) supplemented with a cocktail of protease inhibitors (Roche). Cell lysis was carried out by incubating the cells for $20 \mathrm{~min}$ on ice. Cellular debris was then removed by centrifugation $\left(20,000 \times g, 30 \mathrm{~min}, 4^{\circ} \mathrm{C}\right)$.

The protein samples were resolved in $10 \%$ SDS-PAGE and electro-transferred onto the nitrocellulose membrane in a cooled blotting buffer (0.3\% Tris, $1.44 \%$ glycine, $20 \%$ methanol) at $2.5 \mathrm{~mA} / \mathrm{cm}^{2}$ for $90 \mathrm{~min}$. The membranes were blocked in 5\% non-fat milk in PBS for $1 \mathrm{~h}$. Immunostaining with primary and secondary antibodies was carried out for $1 \mathrm{~h}$ and $30 \mathrm{~min}$, respectively, with extensive washing in PBS after incubation. The membranes were developed using an enhanced chemiluminescence reagent (Thermo Fisher Scientific), and the signal was visualized by an Amersham Imager 600 RGB (GE Healthcare, Chicago, IL, USA). When desired, the membrane was re-probed according to [31]. Briefly, the membrane was washed in PBS, incubated in $30 \%$ peroxide for 15 min at $37^{\circ} \mathrm{C}$, washed twice in water (15 min each washing), and then incubated for $15 \mathrm{~min}$ in PBS, $45 \mathrm{~min}$ in 5\% non-fat milk in PBS, and stained with antibodies. The band intensities of proteins were assessed using the Amersham Imager 600 RGB software and normalized to GAPDH levels (if not stated otherwise). The fold increase in the protein level was compared with that of the control cells. The analyses of all western blots were performed using non-cropped blots, but some blots presented were cropped for clear presentation purposes.

\subsection{Microtubule Pelleting Assay}

Microtubule pelleting assay was performed according to [12,32]. Infected 3T6 cells (40 hpi) or transfected WOP cells (24 hpt) were lysed in a lysis buffer $(20 \mathrm{mM}$ Tris- $\mathrm{HCl} \mathrm{pH}=6.8 ; 140 \mathrm{mM} \mathrm{NaCl}$; $0.5 \% \mathrm{NP}-40 ; 1 \mathrm{mM} \mathrm{MgCl} 2 ; 2 \mathrm{mM} \mathrm{EGTA} ; 4 \mu \mathrm{g} / \mathrm{mL}$ taxol) for $3 \mathrm{~min}$. Lysates were centrifuged for $10 \mathrm{~min}$ at $12,000 \times g, 4{ }^{\circ} \mathrm{C}$ to obtain the soluble fraction (s) and polymerized fraction (p). The equivalent proportions of the $\mathrm{s}$ and $\mathrm{p}$ fractions were resolved by SDS-PAGE and immunoblotted with a specific antibody. The band intensity of each protein was determined using the Amersham Imager 600 RGB software, and the percentage of polymerized tubulin was calculated as $\left(\mathrm{p}_{\text {tubulin }}\right) /\left(\mathrm{s}_{\text {tubulin }}+\mathrm{p}_{\text {tubulin }}\right)$. The fold change of the polymerized tubulin level was compared with the level in the mock-infected or mock-transfected cells, respectively.

\subsection{VP1/EGFP-tVP3 Pentamer Isolation}

The infected cells were harvested at $72 \mathrm{hpi}$, and VP1/EGFP-tVP3 virus like particles were isolated using the standard protocol [25]. To gain pentamers, the particles were dialyzed at $4{ }^{\circ} \mathrm{C}$ for $1.5 \mathrm{~h}$ against dissociation buffer I (20 mM Tris- $\mathrm{HCl}, \mathrm{pH}=8.8 ; 50 \mathrm{mM} \mathrm{NaCl} ; 2 \mathrm{mM}$ DTT; $5 \mathrm{mM}$ EDTA), followed by $1.5 \mathrm{~h}$ dialysis in dissociation buffer II (20 mM Tris- $\mathrm{HCl}, \mathrm{pH}=8.8 ; 50 \mathrm{mM} \mathrm{NaCl} ; 5 \mathrm{mM}$ EDTA). Protein aggregates in the sample were pelleted by centrifugation at $20,000 \times g ; 4^{\circ} \mathrm{C}$ for $30 \mathrm{~min}$. 


\subsection{Direct Immunoelectron Microscopy}

The samples $(10 \mu \mathrm{L})$ were adsorbed on parlodion-carbon-coated grids for 5 min and blocked with 0.5\% BSA in PBS for $30 \mathrm{~min}$. Immunostaining with primary and secondary antibodies was carried out for $1 \mathrm{~h}$ and $30 \mathrm{~min}$, respectively, with washing in PBS (three times for $3 \mathrm{~min}$ ) after incubation. Then, the samples were negatively stained for $1 \mathrm{~min}$ with $2 \%$ phosphotungstic acid two times $(\mathrm{pH}$ 7.3 (Sigma-Aldrich)) and air-dried. Electron micrographs were recorded using a JEM-1011 electron microscope (JEOL, Tokio, Japan) operating at $80 \mathrm{kV}$.

\subsection{Microtubule Preparations}

Tubulin was isolated from pig brains and labeled as described previously [33-35]. For the preparation of biotinylated microtubules, isolated tubulin was mixed with biotinylated tubulin (Cytoskeleton Inc.) at a 50:1 mass ratio. For the preparation of rhodamine-labeled microtubules, isolated tubulin was mixed with rhodamine-labeled tubulin (Cytoskeleton Inc.) at a 5:1 mass ratio. GMPCPP-stabilized microtubules were grown using a mixture of $1.3 \mathrm{mg} / \mathrm{mL}$ tubulin and $2 \mathrm{mM}$ GMPCPP (guanosine-5'-[( $\alpha, \beta)$-methyleno]triphosphate, Merck Millipore, Billerica, MA, USA) in a BRB80 buffer ( $80 \mathrm{mM}$ Pipes, $\mathrm{pH}=6.8,2 \mathrm{mM} \mathrm{MgCl}, 1 \mathrm{mM}$ EGTA) and incubated for $1 \mathrm{~h}$ for the microtubule binding assay or $15 \mathrm{~min}$ for the dynamic microtubule assay at $37^{\circ} \mathrm{C}$. The mixture was then spun at $14,000 \times g$. Finally, the supernatant was discarded, and the pellet was resuspended in 50 $\mu \mathrm{L}$ BRB80 buffer.

\subsection{Total Internal Reflection Fluorescence (TIRF) Microscopy}

Imaging was carried out at room temperature using an inverted microscope (Nikon, Ti-E Eclipse) equipped with a $100 \times$ or $60 \times 1.49$ N.A. oil immersion objective (Nikon, Plan Apo) and an electron multiplying CCD camera (Andor Technology, iXon Ultra 888). The samples were excited using a LU-N4/N4S laser unit (Nikon). Illumination and image acquisition were controlled by NIS Elements Advanced Research software (Nikon). Rhodamine-labeled microtubules and EGFP-labeled proteins were visualized sequentially by switching between a $561 \mathrm{~nm}$ and $488 \mathrm{~nm}$ laser and changing the filter set. The acquisition rates were one frame per $10 \mathrm{~s}$. The flow chambers for the TIRF imaging assays were prepared as described previously [36,37]. The channels were treated with an anti- $\beta$-tubulin antibody (1 $\mathrm{mg} / \mathrm{mL}$ in PBS) or anti-biotin (1 mg/mL in PBS) solution for $5 \mathrm{~min}$, followed by one-hour incubation with 1\% Pluronic F127 (Sigma-Aldrich). For the microtubule binding assay, the channels were each washed with $40 \mu \mathrm{L}$ BRB80 buffer with a subsequent injection of rhodamine-labeled microtubules. Then, the channels were flushed with $20 \mu \mathrm{L}$ BRB80 buffer to remove unbound microtubules. Finally, the flow chamber was suffused with VP1/EGFP-tVP3 pentamers diluted in an assay buffer (BRB80 supplemented with $0.5 \mathrm{mg} / \mathrm{mL}$ casein, $10 \mathrm{mM}$ dithiothreitol, 0.1\% Tween-20, $20 \mathrm{mM}$ D-glucose, $22.4 \mu \mathrm{g} / \mathrm{mL}$ glucose oxidase, $20 \mu \mathrm{g} / \mathrm{mL}$ catalase, and $1 \mathrm{mM}$ ATP). For the dynamic microtubule assay, the channels were each washed with $40 \mu \mathrm{L}$ BRB80 buffer with a subsequent injection of biotinylated unlabeled microtubules. Then, the channels were flushed with $20 \mu \mathrm{L}$ BRB80 buffer to remove unbound microtubules. Finally, the flow chamber was suffused with a mixture of $15 \mu \mathrm{M}$ rhodamine-labeled tubulin and VP1/EGFP-tVP3 diluted in a polymerization buffer (BRB80 supplemented with $20 \mathrm{mM}$ D-glucose, $22.4 \mu \mathrm{g} / \mathrm{mL}$ glucose oxidase, $20 \mu \mathrm{g} / \mathrm{mL}$ catalase, $1 \mathrm{mM}$ ATP and $1 \mathrm{mM}$ GTP).

\subsection{Tubulin-VP1 Co-Sedimentation Assay}

To perform the VP1 co-sedimentation assay, first $1.8 \mu \mathrm{g}$ VP1/EGFP-tVP3 and $50 \mu \mathrm{g}$ unlabeled porcine tubulin were mixed in a $20 \mu \mathrm{L}$ BRB80 buffer. The mixture was incubated for $10 \mathrm{~min}$ at room temperature. The samples were then spun at $50,000 \times g, 30 \mathrm{~min}$. Then, the supernatants were separated from the pellets, and the pellets were resuspended in $20 \mu \mathrm{L}$ BRB80 buffer. Finally, $10 \mu \mathrm{L}$ of each supernatant and pellet fraction was analyzed by SDS-PAGE. 


\subsection{Nocodazole Sensitivity Assay}

A nocodazole sensitivity assay was performed according to [12]. WOP cells were transfected with pVP1 and treated with $4 \mu \mathrm{M}$ nocodazole (Merck Millipore) $24 \mathrm{~h}$ post transfection for $5,10,20$, or $60 \mathrm{~min}$. To remove soluble tubulin, cells were rinsed twice with a PHEM buffer (60 mM PIPES; 25 mM HEPES; $4 \mathrm{mM} \mathrm{MgSO}_{4} ; 10 \mathrm{mM}$ EGTA; $\mathrm{pH}=7.0$ ) and then extracted for $1 \mathrm{~min}$ with a PHEM buffer supplemented with $0.2 \%$ Triton X-100. The extraction of nocodazole-treated cells was performed in a buffer supplemented with nocodazole at the same concentration used for the treatment to prevent the polymerization of the microtubules during extraction. After the extraction of free tubulin, the cells were fixed, and VP1 and tubulin were stained by specific antibodies.

To quantify the number of microtubules in the cells expressing VP1, the transfected cells were treated with $4 \mu \mathrm{M}$ nocodazole for $30 \mathrm{~min}$. After the treatment, the cells were scraped into the media and pelleted by centrifugation ( $5 \mathrm{~min} ; 200 \times \mathrm{g}$ ). The cells were resuspended in $250 \mu \mathrm{L}$ of PHEM buffer supplemented with $0.2 \%$ Triton X-100 and a cocktail of protease inhibitors (Roche) and immediately centrifuged for $1 \mathrm{~min}$ at $16,000 \times \mathrm{g}$. A supernatant (containing a soluble tubulin fraction) was designated as the $s$ fraction. The pellet was resuspended in $250 \mu \mathrm{L}$ ice-cold RIPA buffer, lysed for $20 \mathrm{~min}$ on ice, and designated as the $\mathrm{p}$ fraction. The equivalent proportions of the $\mathrm{s}$ and $\mathrm{p}$ fractions were resolved by SDS-PAGE and immunoblot was analyzed with a specific antibody. The band intensity of each protein was determined using the Amersham Imager 600 RGB software, and the percentage of polymerized tubulin was calculated as $\left(\mathrm{p}_{\text {tubulin }}\right) /\left(\mathrm{s}_{\text {tubulin }}+\mathrm{p}_{\text {tubulin }}\right)$. The fold change in the level of polymerized tubulin was compared with the level in the mock-treated $(t=0 \mathrm{~min})$ cells. Statistical relevance was tested by an independent Student's two-sample $t$-test with a significance value of $p<0.05$.

\subsection{Impact of HDAC6 Inhibition on Viral Protein Levels and Virus Production}

Mouse fibroblasts 3T6 and 3T3-wt or $\alpha$ TAT1 KO were infected and24 hpi the media were supplemented with tubacin to achieve a final concentration of $5 \mu \mathrm{M}$. The cells were left with tubacin for an additional $16 \mathrm{~h}$ or $24 \mathrm{~h}$. Cells were lysed at $40 \mathrm{hpi}$ (16 h treatment). Then, the lysates were resolved in $10 \%$ SDS-PAGE gel, transferred to the membrane, and the proteins were detected by specific antibodies. The band intensity of each protein was determined using the Amersham Imager 600 RGB software and normalized to GAPDH levels. The fold increase in the protein level was compared with that in the

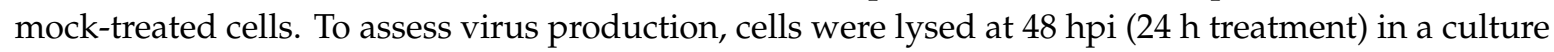
media using three freeze-thaw cycles. Cellular debris was removed by centrifugation $(8000 \times g ; 10 \mathrm{~min}$; $4{ }^{\circ} \mathrm{C}$ ), and supernatant was used as a virus inoculum in the subsequent experiments. $3 \mathrm{~T} 6$ cells were infected with equal amount of virus inocula. Then, cells were fixed at $24 \mathrm{hpi}$, and the LT antigen was stained by specific antibodies. The numbers of infected cells were scored by immunofluorescence microscopy. At least 300 cells were counted for each experiment, and the amounts of infectious viral particles in the viral inocula were assessed. The amount of the virus produced in the tubacin treated cells was compared with that produced in the mock-treated cells.

\subsection{Significance of Acetylated Microtubules for Viral Proteins and Virus Production}

The 3T3-wt, $\alpha$ TAT1 KO, WOP, WOP-EGFP- $\alpha$ TAT1 cells, or WOP cells expressing EGFP, were infected. The cells were lysed at $40 \mathrm{hpi}$. Then, the lysates were resolved in 10\% SDS-PAGE gel, transferred to membrane, and the proteins were detected by specific antibodies. The band intensities of the proteins were determined using the Amersham Imager 600 RGB software and normalized to GAPDH levels. The fold increase in the proteins was compared with their levels in the 3T3-wt or WOP cells. To assess virus production, cells were lysed at $48 \mathrm{hpi}$ in a culture media using three freeze-thaw cycles. Cellular debris was removed by centrifugation $\left(8000 \times g ; 10 \mathrm{~min} ; 4^{\circ} \mathrm{C}\right)$, and a supernatant was used as the virus inoculum in the subsequent experiments. 3T6 cells were infected with equal amount of the virus inoculum, cells were fixed at $24 \mathrm{hpi}$, and the LT antigen was stained with specific antibodies. The numbers of infected cells were scored by immunofluorescence microscopy. At least 300 
cells were counted per experiment, and the amount of infectious viral particles in the viral inoculum was assessed. The amount of virus produced in the cells was compared with that produced in the 3T3-wt or WOP cells.

\subsection{Statistical Analysis}

Data are presented as the mean values from three independent experiments, unless otherwise noted. The error bars represent SD. Student's $t$-test was performed using the GraphPad Prism software, version 6.0 (GraphPad Software, La Jolla, CA, USA). ${ }^{*} p<0.05,{ }^{* *} p<0.01,{ }^{* * *} p<0.001,{ }^{* * * *} p<0.0001$ were considered to be significant.

\section{Results}

\subsection{Microtubule Acetylation Gradually Increases during the Late Phase of Infection}

Our previous research showed that microtubule acetylation is elevated in cells expressing VP1. In this study, we examined microtubule acetylation in the late phase of MPyV infection in detail. Infected cells were harvested in 8-h intervals, and the amounts of tubulin, acetylated $\alpha$-tubulin, and VP1 were analyzed by Western blot. The levels of acetylated $\alpha$-tubulin and tubulin were compared with the levels of these proteins in mock infected cells at 24 hpi. The levels of VP1 were related to the VP1 levels at $8 \mathrm{hpi}$. At this time point, most of the input viral particles became cleared by cells and only particles which were released from endoplasmic reticulum to the cytosol from where their genomes can be delivered to the cell nucleus were present in the cells. Together with increasing levels of VP1, the number of acetylated microtubules increased gradually and reached its peak value at 40 hpi (Figure 1). Although the level of acetylated $\alpha$-tubulin was elevated, the amount of tubulin remained invariable during the late phase of MPyV infection (Figure 1B,D).

A

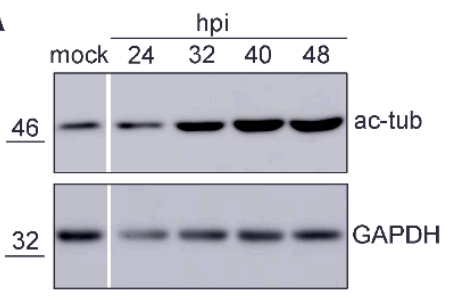

B

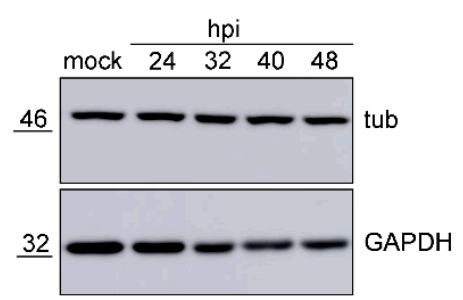

C

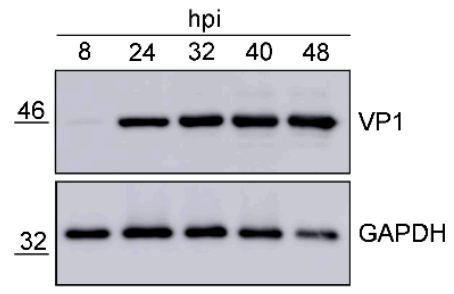

D

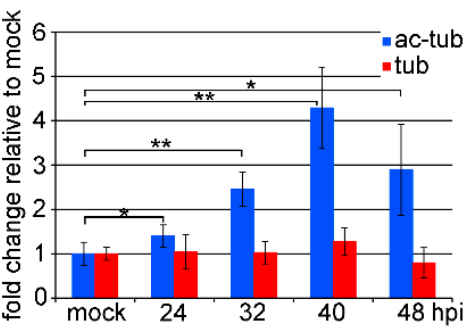

E

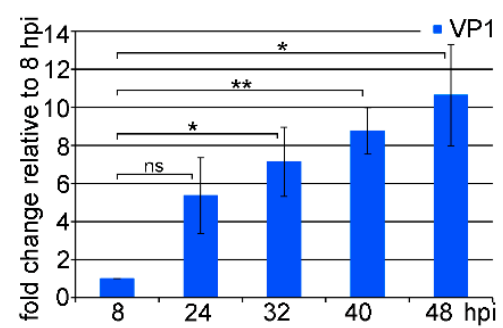

Figure 1. The acetylation of microtubules was elevated during the late phase of infection. (A-C) 3T6 cells were infected with MPyV and lysed at the indicated hours post infection (hpi). Lysates were separated by SDS/PAGE, transferred onto membrane, and acetylated tubulin (ac-tub), tubulin (tub), VP1, and GAPDH were stained by specific antibodies. (D,E) A graphic illustration of a densitometry analysis of the digital images of Western blots from four independent experiments. Shown is the fold increase relative to mock-infected cells (a representative $24 \mathrm{~h}$ time point) (D) or infected cells at $8 \mathrm{hpi}$ (representing amount of incoming virus) (E). $+/-$ SD. ${ }^{*} p<0.05,{ }^{* *} p<0.01$, determined by the Student's $t$ test. The changes in total levels of tubulin (D, red columns) were not significant (ns) according to the analysis using the Student's $t$ test. 


\section{2. mRNA Levels of HDAC6 and $\alpha$ TAT1 Are Not Affected in the Late Phase of MPyV Infection}

Next, we were interested in whether the elevated level of microtubule acetylation is caused by the deregulation of the expression of deacetylating (HDAC6) and/or acetylating ( $\alpha$ TAT1) enzymes. As shown in Figure 2, despite a marked increase in microtubule acetylation, the mRNA levels of both enzymes were not significantly affected during the late phase of infection (Figure 2).

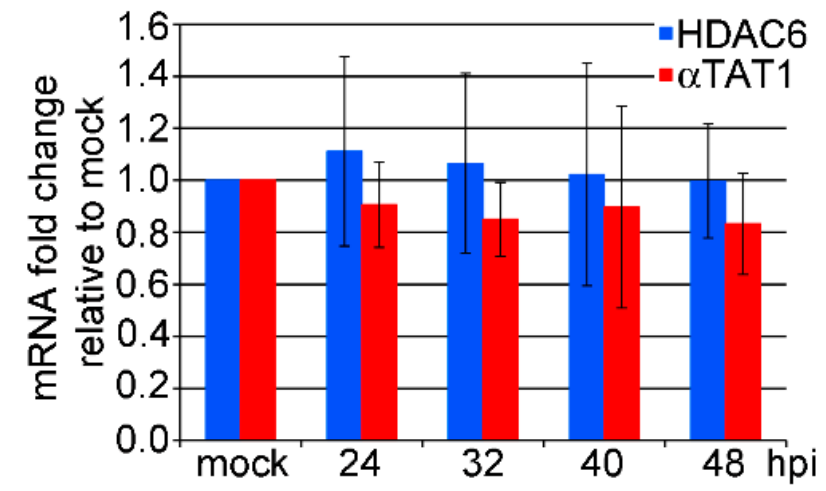

Figure 2. VP1 expression does not change the mRNA levels of either $\alpha$-tubulin acetyltransferase 1 $(\alpha \mathrm{TAT} 1)$ or histone deacetylase 6 (HDAC6). 3T6 cells were infected, and the levels of HDAC6 or $\alpha$ TAT1 mRNA were measured by qPCR at the indicated times post infection. Data represent the fold change relative to the mock-infected cells from four independent experiments +/- SD. Data were not significant according to the analysis using Student's $t$ test.

These data show that considerably higher microtubule acetylation is not realized by the deregulation of HDAC 6 and/or $\alpha$ TAT1 gene expression but rather by affecting HDAC 6 and/or $\alpha$ TAT1 enzymatic activity. Our previous study indicated that VP1-microtubule binding may increase microtubule stability. Furthermore, Coombes et al. [38] observed that microtubule acetylation gradually accumulates on a stable subset of microtubules in the cell. Stable microtubules can then serve as a support for $\alpha$ TAT1 activity, resulting in elevated levels of microtubule acetylation.

\subsection{Amount of Microtubules is Increased in Cells Expressing VP1}

We next analyzed whether VP1 production elevates the levels of polymerized tubulin in cells, thereby increasing the level of the preferred substrate for $\alpha \mathrm{TAT} 1$. MPyV-infected cells and cells expressing VP1 only were used for fractionation. Mouse 3T6 fibroblasts, permissive for MPyV, were used for all experiments in the infection studies. Unfortunately, their transfection efficiency was low (20-25\%). Therefore, highly transfectable (85-90\%) WOP cells (3T3 fibroblasts constitutively expressing the large $\mathrm{T}$ antigen of MPyV) were used for transient VP1 expression studies. After fractionation, the amount of tubulin in the polymerized and soluble fraction was measured by Western blot analysis. In the infected cells, the number of microtubules was approximately two times higher than that in the mock-infected cells (Figure 3A,B). Accordingly, in cells transiently expressing VP1, the number of microtubules was two times higher than that in the mock-transfected cells (Figure 3C,D). These data suggest that VP1 induces the stability of the microtubules affecting their dynamics. 
A

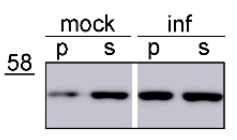

B

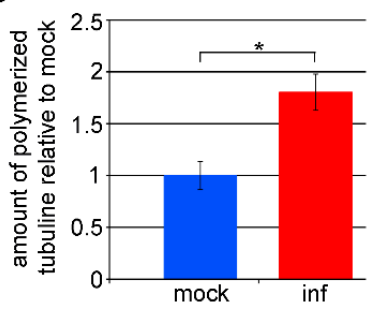

C

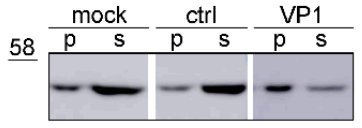

D

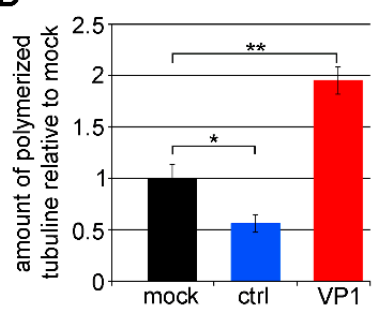

Figure 3. VP1 increases the level of microtubules in cells. (A) 3T6 cells were infected or (C) WOP cells were transfected with the control plasmid (ctrl) or with the plasmid expressing VP1 (VP1). Cells were fractionated into a polymerized (p) and soluble (s) fraction at $40 \mathrm{hpi}$ or $24 \mathrm{hpt}$. These fractions were applied to SDS-PAGE, immunoblotted, and tubulin was stained by a specific antibody. (B,D) A graphic illustration of a densitometry analysis of the digital images of Western blots from three independent experiments. The fold increase in polymerized tubulin relative to the mock-infected/mock-transfected cells is shown. $+/-\mathrm{SD} .{ }^{*} p<0.05,{ }^{* *} p<0.01$ determined by Student's $t$ test.

\subsection{VP1 Binds Microtubules Directly and Stabilizes Them}

To investigate whether VP1 binds microtubules directly and how it affects microtubule dynamics, we used an in vitro VP1-microtubule binding assay. As both infectious viral particles [39,40] and VLPs [41] are assembled in the cell's nucleus after the transportation of capsomeres formed in the cytoplasm, we assumed that in the cytoplasm of cells, VP1 interacts with microtubule structures mostly in the form of capsomeres. For the preparation of capsomeres, VP1/EGFP-tVP3 virus-like particles were isolated from insect cells infected with recombinant baculovirus and disassembled into capsomeres (Figure S1). These particles were designed to contain EGFP as fusion protein with the common short $\mathrm{C}$ - terminus sequence of the minor capsid proteins responsible for their interaction with the central cavity of VP1 pentameric capsomeres [25].

To visualize the interaction of VP1/EGFP-tVP3 capsomeres with microtubules, we immobilized the taxol-stabilized rhodamine-labeled microtubules on the surface of the flow chamber with anti- $\beta$-tubulin antibodies; then, we flushed in VP1/EGFP-tVP3 diluted in an assay buffer and visualized the system by TIRF microscopy (Figure 4A). At $3.65 \mu \mathrm{g} / \mathrm{mL}$ VP1/EGFP-tVP3, we observed VP1/EGFP-tVP3 binding directly to the microtubules (Figure 4B). No interaction between the isolated EGFP and the microtubules was detected [42]. Next, to test if VP1/EGFP-tVP3 capsomeres stabilize the microtubules, we flushed a taxol-free assay buffer without or with $3.65 \mu \mathrm{g} / \mathrm{mL} \mathrm{VP1/EGFP-tVP3} \mathrm{in} \mathrm{the} \mathrm{channel} \mathrm{with} \mathrm{taxol-stabilized}$ microtubules. While in the absence of VP1/EGFP-tVP3, the microtubules disassembled rapidly, in the presence of VP1/EGFP-tVP3, the microtubules did not exhibit any observable depolymerization (Figure 4C).

Furthermore, we examined whether VP1 binding affects microtubule dynamics using a microtubule dynamics assay. In the absence or presence of VP1/EGFP-tVP3, we introduced $15 \mu \mathrm{M}$ rhodamine-labeled porcine tubulin in a polymerization buffer to GMPCPP-stabilized microtubule seeds immobilized on the coverslip and followed this process by TIRF microscopy. In this experiment, we did not observe any VP1/EGFP-tVP3 particles bound to the microtubules at a concentration of $3.65 \mu \mathrm{g} / \mathrm{mL}$ VP1/EGFP-tVP3, although there was a substantial decrease in microtubule polymerization time at both the plus and minus tips (Figure 4D,E). Furthermore, we observed almost no polymerization at a concentration of $9.13 \mu \mathrm{g} / \mathrm{mL}$ VP1/EGFP-tVP3 and only faint binding to the microtubules. This suggests that VP1/EGFP-tVP3 binds free tubulin, depleting it from the solution and hindering microtubule dynamics. To prove this, we performed a co-sedimentation assay. We incubated a mixture of VP1/EGFP-tVP3 with unlabeled porcine tubulin, sedimented it by centrifugation, and analyzed the sediment and supernatant by SDS-PAGE. While the tubulin without the presence of VP1/EGFP-tVP3 remained mostly in the supernatant, both components of the mixture of VP1/EGFP-tVP3 with tubulin appeared fully in the pellet (Figure 4F). 
A

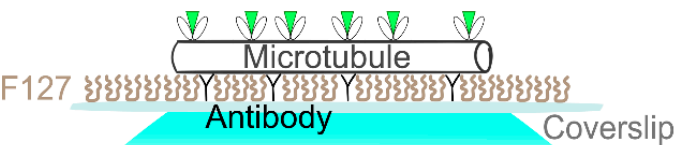

TIRF laser

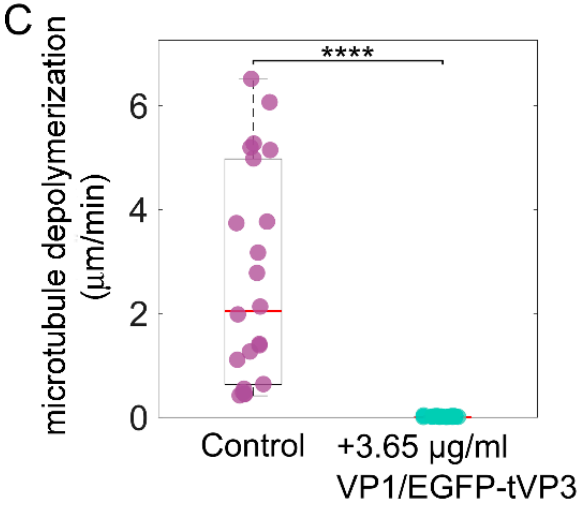

B
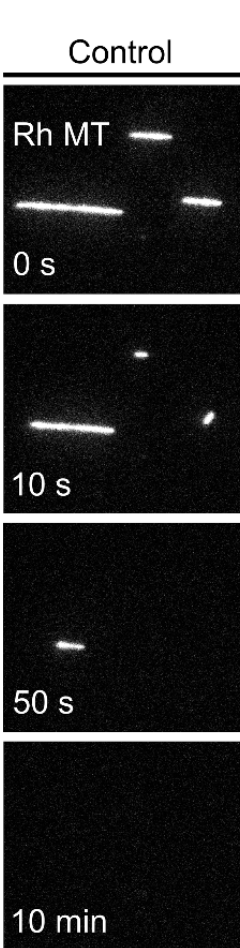

$15 \mu \mathrm{M}$ Rh tub + $15 \mu \mathrm{M}$ tub

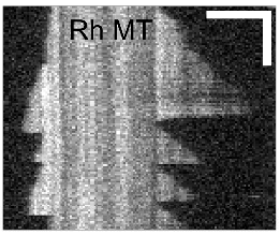

E

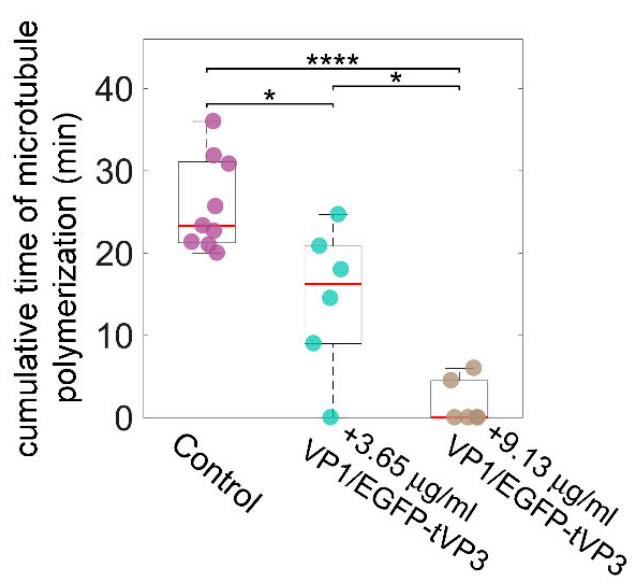

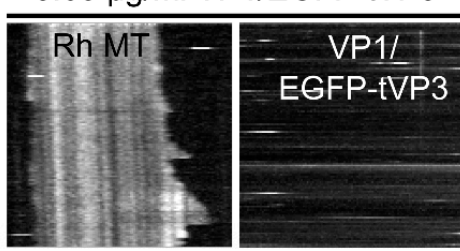

F

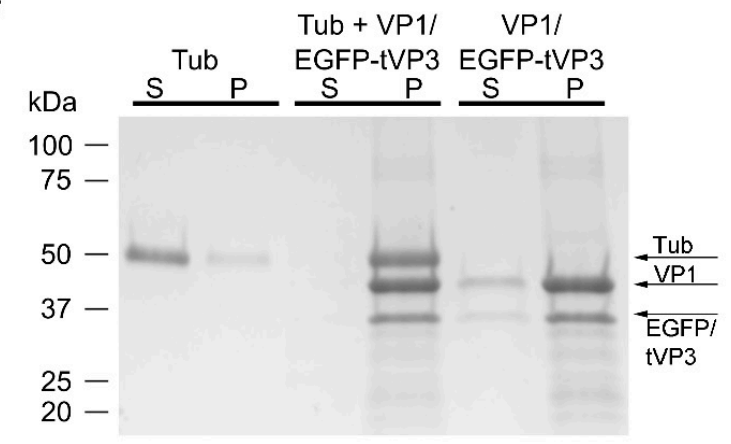

Figure 4. VP1 directly binds microtubules and stabilizes them. (A) A schematic diagram of a microtubule binding assay with VP1/EGFP-tVP3. (B) Time-lapse fluorescence micrographs of rhodamine-labeled microtubules (Rh MT) depolymerizing in the absence or presence of $3.65 \mu \mathrm{g} / \mathrm{mL}$ VP1/EGFP-tVP3. Scale bar, $10 \mu \mathrm{m}$. (C) Depolymerization rates of taxol-stabilized rhodamine-labeled microtubules in the absence (control) or presence of $3.65 \mu \mathrm{g} / \mathrm{mL}$ VP1/EGFP-tVP3. Control: $2.67 \pm 2.07 \mu \mathrm{m} / \mathrm{min}(N=22)$. Microtubules $+3.65 \mu \mathrm{g} / \mathrm{mL}$ VP1/EGFP-tVP3: $0.01 \pm 0.01 \mu \mathrm{m} / \mathrm{min}(N=16)$; values are the mean \pm SD . Red lines represent the median values; the bottom and top edges of the box indicate the 25th and 75th percentiles, respectively. The whiskers extend to the extreme data points. (D) Kymographs showing dynamic microtubules polymerizing with $15 \mu \mathrm{M}$ free rhodamine-labeled tubulin in the absence or 
presence of 3.65 or $9.13 \mu \mathrm{g} / \mathrm{mL}$ VP1/EGFP-tVP3. Horizontal scale bar $3 \mu \mathrm{m}$; vertical bar $5 \mathrm{~min}$. (E) Cumulative polymerization time of both microtubules' plus and minus tips over $20 \mathrm{~min}$ in the absence or presence of 3.65 or $9.13 \mu \mathrm{g} / \mathrm{mL}$ VP1/EGFP-tVP3. Tubulin $(15 \mu \mathrm{M})$ control: $25.85 \pm 5.68(N=9)$, tubulin $(15 \mu \mathrm{M})+3.65 \mu \mathrm{g} / \mathrm{mL}$ VP1/EGFP-tVP3: $14.5 \pm 8.91(N=6)$, tubulin $(15 \mu \mathrm{M})+9.13 \mu \mathrm{g} / \mathrm{mL}$ VP1/EGFP-tVP3: $1.75 \pm 2.75(N=6)$; values are the mean \pm SD. Red lines represent median values; the bottom and top edges of the box indicate the 25th and 75th percentiles, respectively. The whiskers extend to the extreme data points. (F) Coomassie-stained SDS-polyacrylamide gel electrophoresis (SDS-PAGE) of $5 \mathrm{mg} / \mathrm{mL}$ unlabeled porcine tubulin, $182.5 \mu \mathrm{g} / \mathrm{mL}$ VP1/EGFP-tVP3, or their mixture, after the VP1-co-sedimentation assay. Supernatant fraction (s) and pellet (p). In (C) and (E), ${ }^{*} p<0.05$, **** $p<0.0001$, determined by Student's $t$ test.

The stability of microtubules was further confirmed at a cellular level using a nocodazole sensitivity assay. VP1-expressing cells were treated with the microtubule-destabilizing drug nocodazole for 5, 20, 40, and $60 \mathrm{~min}$. After the treatment, cells were extracted to remove free tubulin, whose bright diffuse staining would otherwise obscure the microtubules [12]. The extracted cells were fixed, and the microtubules and VP1 were stained by specific antibodies. The microtubules were observed in non-treated cells ( $t=0 \mathrm{~min}$ ) and in cells treated for 5 min with nocodazole in cells expressing VP1, as well as in the control mock-transfected cells (Figure 5A). During the course of exposure to nocodazole, almost all microtubules disappeared in the mock-transfected cells, while many microtubules were observed in VP1-expressing cells (Figure 5A). To quantify microtubule depletion, the total number of microtubules remaining in the cells after 30 min of nocodazole treatment was measured by Western blot. In the mock-transfected cells, the amount of microtubules declined by 64\%, whereas, in VP1-expressing cells, the amount of microtubules declined by only $43 \%$ (Figure 5B,C).

Taken together, these data show that VP1 binds microtubules (and tubulin) directly, which leads to their stabilization and an increase in the microtubule level within the cells.

\subsection{VP1 Stimulates Hyperacetylation of Microtubules}

In a previous study [3], we performed an in situ fractionation of infected cells and showed that a subpopulation of tubulin accumulates in the last insoluble fraction together with VP1. This method is based on the successive washing out of proteins according to their solubility in different buffers. The last fraction, soluble only by SDS, contains highly insoluble protein complexes. Here, we address whether the tubulin in the VP1-microtubule insoluble complex is more acetylated than the last fraction of microtubules in the control (VP1 negative) cells. Therefore, the VP1 positive and control cells were again in situ fractionated, and each fraction was analyzed by Western blot to determine the levels of VP1 and tubulin. VP1 was detected in all fractions of both infected cells and cells transiently producing VP1. The highest VP1 level was detected in the last SDS fraction (Figure 6A,E). Although tubulin was detected in the SDS fraction in the mock-infected or mock-transfected cells, the amount of tubulin was significantly higher in the VP1-producing cells (by almost two times in the infected and four times in the transfected cells) (Figure 6A,B,E,F). Western blot analysis of the SDS solubilized fractions with the antibody directed against acetylated $\alpha$-tubulin revealed that the level of acetylated tubulin was 2.5-times higher in the VP1 positive cells compared to that in the control (VP1 negative) cells (Figure 6C,D,G,H). 

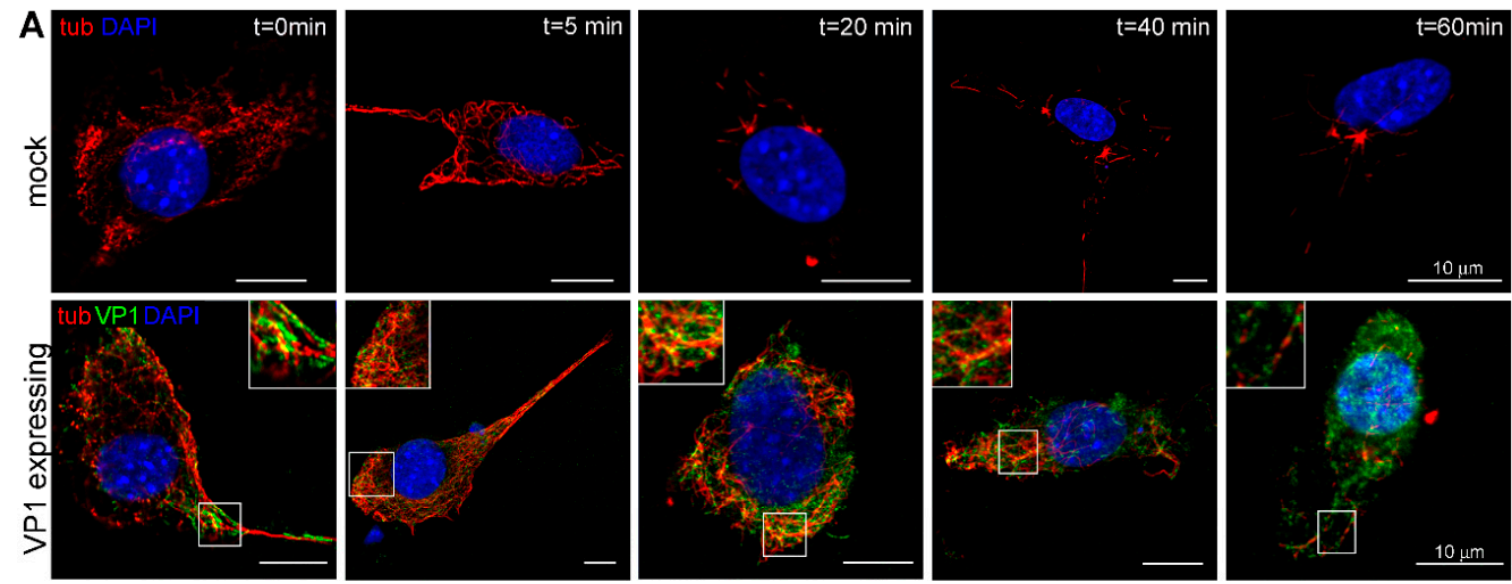

B

C
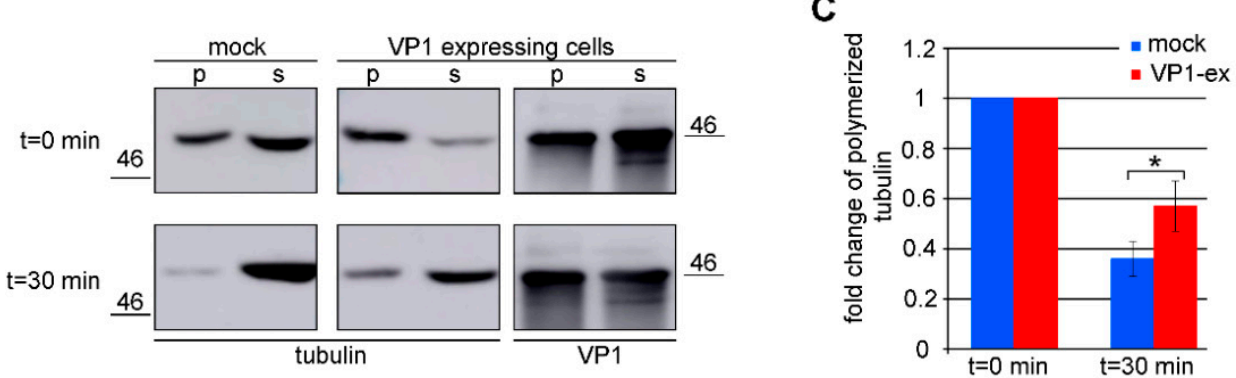

Figure 5. VP1 protects microtubules from nocodazole induced depolymerization. WOP cells were transfected with plasmids expressing VP1 and $24 \mathrm{hpt}$ cells were treated with nocodazole $(4 \mu \mathrm{M})$ for the indicated times. (A) After the treatment, soluble tubulin was washed out, the cells were fixed, and polymerized tubulin (tub; red) and VP1 (green) were stained by specific antibodies. Shown are the selected confocal sections. Enlarged details of the cells are presented in insets. Bar: $10 \mu \mathrm{m}$. (B) After the treatment, cells were fractionated into a soluble tubulin fraction (s) and polymerized tubulin fraction (p). Equal amounts of the fractions were resolved via SDS/PAGE, immunoblotted, and tubulin and VP1 were stained with specific antibodies. (C) A graphic illustration of a densitometry analysis of the digital images of Western blots from three independent experiments. The fold change in polymerized tubulin relative to the mock-treated cells $(t=0 \mathrm{~min})$ is shown. $+/-\mathrm{SD} ;{ }^{*} p<0.05$ determined by Student's $t$ test.

We were further interested in whether $\alpha$ TAT1 is a part of the VP1-microtubule complex. To easily track $\alpha$ TAT1 in cells, a WOP cell line stably overexpressing $\alpha$ TAT1 fused with EGFP was established. The overexpression of $\alpha$ TAT1 in WOP-EGFP- $\alpha$ TAT1 cells was confirmed by a Western blot analysis of cell lysates using an antibody specific to EGFP (Figure 6I, Figure 7L). WOP-EGFP- $\alpha$ TAT1 cells were in situ fractionated, and the presence of $\alpha$ TAT1 was examined. EGFP- $\alpha$ TAT1 was detected convincingly in only the last insoluble fraction. As seen in Figure 6J, EGFP- $\alpha$ TAT1 was detected in the SDS fractions of VP1 positive cells but not in mock infected or transfected cells. Nevertheless, in pooled fractions, EGFP- $\alpha$ TAT1 could be detected in both VP1-negative mock-infected cells and VP1-producing infected or transfected cells (Figure 6J). These data show that microtubules in the VP1-microtubule complex are acetylated. This high acetylation is obviously supported by $\alpha$ TAT1, which is also part of the complex, and its activity is stimulated by VP1-mediated microtubule stabilization. 
A

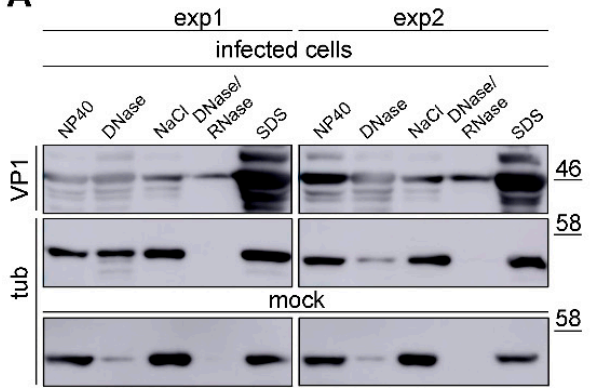

E

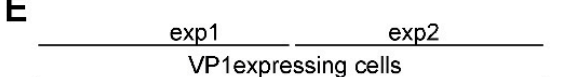
VP1expressing cells

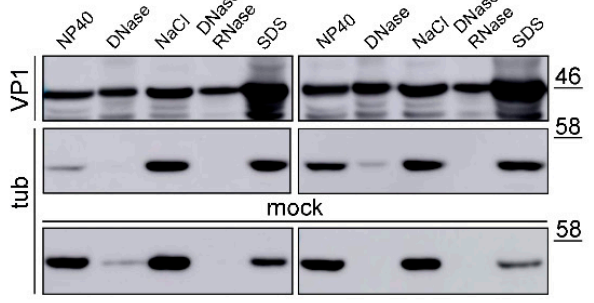

I

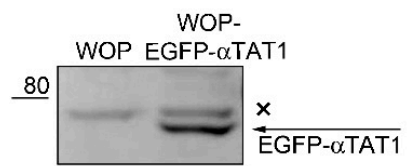

J
B

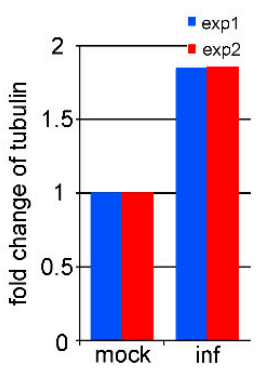

F

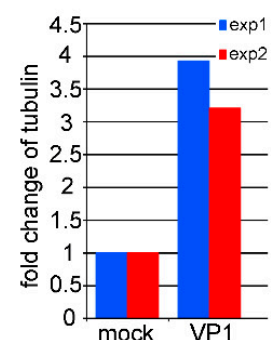

C

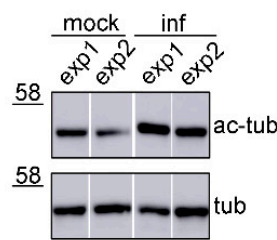

G

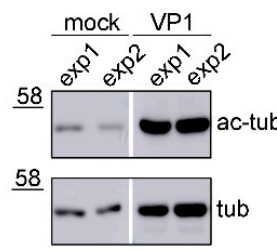

D

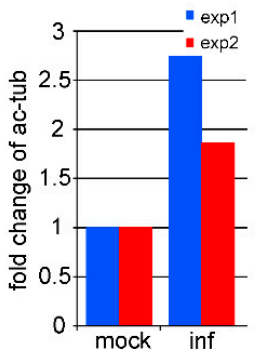

H

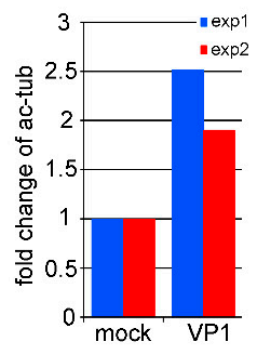

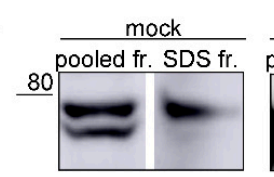

VP1 expressing pooled fr. SDS fr.

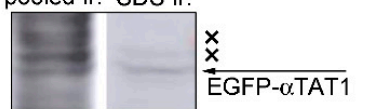

Figure 6. $\alpha$ TAT1 is a part of the VP1-hyperacetylated microtubule complex. (A,E) Infected 3 T6 cells (A) or VP1 expressing cells (E) were in situ fractionated; then, an equal amount of washed out material from each fraction was separated via SDS/PAGE and transferred onto the membrane. The presence of VP1 and tubulin (tub) in each fraction was determined by specific antibodies. (B,F) A graphic illustration of the densitometry analysis of the digital images of Western blots from two independent experiments. Presented are the fold changes of tubulin in the SDS fraction of the infected (B) or VP1-expressing cells (F), which were compared with mock-infected or mock-transfected cells. $(\mathbf{C}, \mathrm{G})$ An equal amount of the SDS fraction from infected (inf) (C) or VP1-expressing cells (VP1) (G) was resolved on SDS/PAGE, immunoblotted to the membrane and tubulin, and acetylated $\alpha$-tubulin (ac-tub) was stained by specific antibodies. $(\mathbf{D}, \mathbf{H})$ A graphic illustration of the densitometry analysis of the digital images of Western blots from two independent experiments. Presented are the fold changes of $\alpha$-tubulin acetylation ratios in the SDS fraction of the infected (D) or VP1-expressing cells $(\mathbf{H})$, which were compared with those of the mock-infected or mock-transfected cells. (I) Lysates of WOP and WOP-EGFP- $\alpha$ TAT1 were separated by SDS/PAGE, blotted onto the membrane, and EGFP was stained by a specific antibody. (J) Infected (inf) or VP1-expessing cells were in situ fractionated, and equal amounts of the pooled fractions and SDS fraction were separated by SDS/PAGE, transferred onto the membrane, and EGFP was stained by a specific antibody; $\times$ indicates non-specific antibody staining. 
A

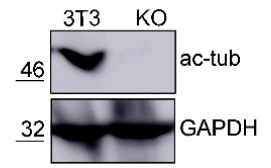

B

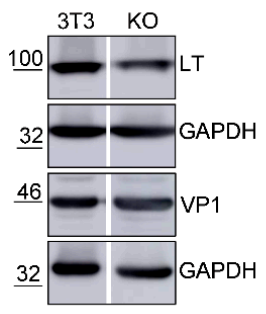

C

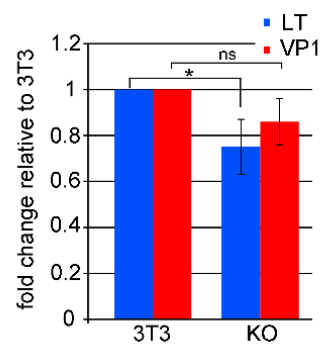

D

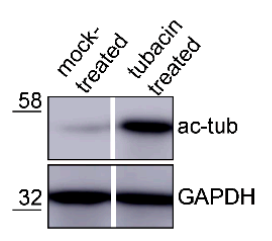

H

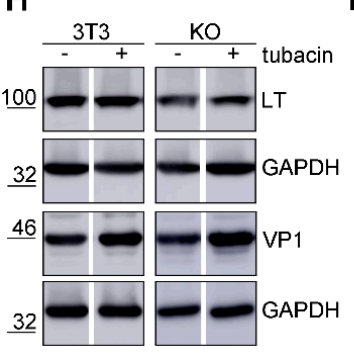

L

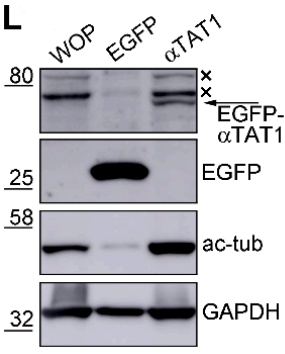

E

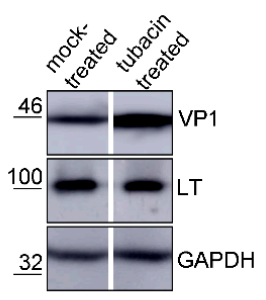

F

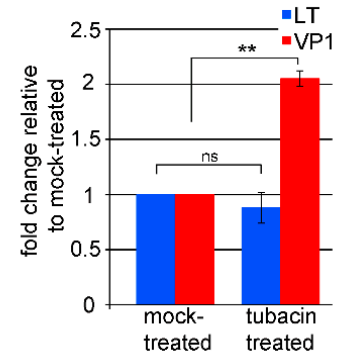

J

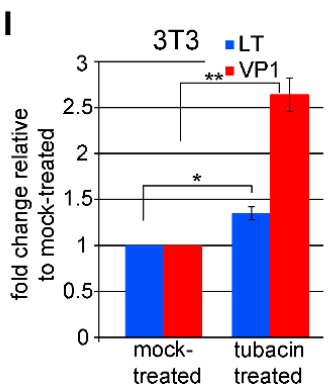

M

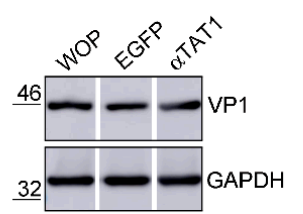

\section{$\checkmark$}

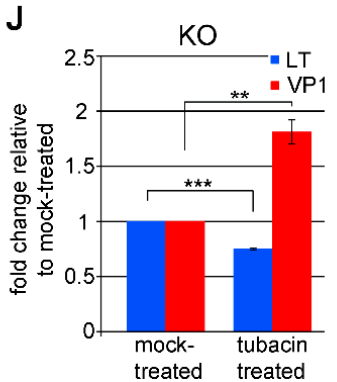

N

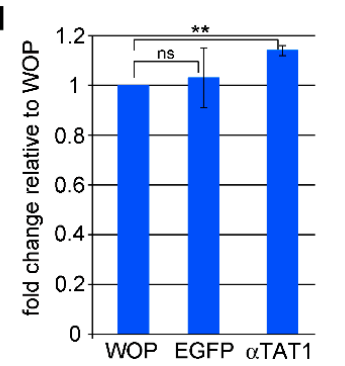

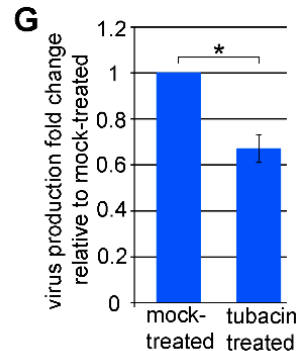

K
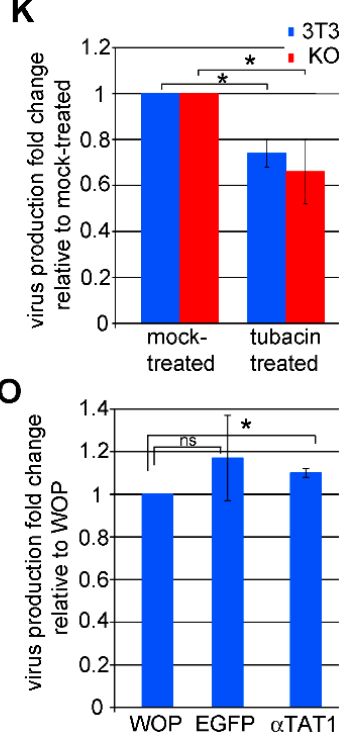

Figure 7. Acetylated microtubules are dispensable for MPyV infection. (A) Lysates of 3T3-wt and $\alpha$ TAT1 KO cells were separated by SDS/PAGE, blotted onto the membrane, and acetylated $\alpha$-tubulin (ac-tub) and GAPDH were stained by specific antibodies. (B) Lysates (40 hpi) of infected 3T3-wt and $\alpha$ TAT1 KO cells were resolved on SDS/PAGE, transferred onto the membrane, and VP1, LT, and GAPDH were stained by specific antibodies. (C) A graphic illustration of the densitometry analysis of the digital images of Western blots of three independent experiments. The fold change relative to 3T3-wt cells $+/-\mathrm{SD}$ is shown. (D) Lysates of $3 \mathrm{~T} 6$ cells treated for $24 \mathrm{~h}$ with $5 \mu \mathrm{M}$ tubacin were separated by $10 \%$ SDS/PAGE, transferred onto a membrane, and acetylated $\alpha$-tubulin and GAPDH were stained by specific antibodies. (E,H) 3T6 (E), 3T3-wt, and $\alpha$ TAT1 KO cells (H) were infected, and 24 hpi tubacin was added $(5 \mu \mathrm{M})$. Cells were lysed after $16 \mathrm{~h}$ tubacin treatment, lysates were separated by SDS/PAGE and immunoblotted, and VP1, LT, and GAPDH were stained by specific antibodies. (F,IJ) Graphic illustration of the densitometry analysis of the digital images of the Western blots of three independent experiments. Shown is the fold change relative to the mock treated 3T6 (F), 3T3-wt, (I) and $\alpha$ TAT1 KO (J) cells +/- SD. (G,K) Cells 3T6 (G), 3T3-wt, and $\alpha$ TAT1 KO cells (K) were infected; then, 24 hpi tubacin was added $(5 \mu \mathrm{M})$, and, after $24 \mathrm{~h}$ of incubation, MPyV virions were isolated. 3T6 cells were infected with equal volumes of the virus isolated from the tubacin treated or mock-treated cells. Cells were fixed at $24 \mathrm{hpi}$, and the LT antigen was stained by a specific antibody. The values in the graph refer to the fold change in numbers of LT positive cells relative to the mock-treated cells and represent the mean 
values from three independent experiments +/- SD. (L) Lysates of WOP, WOP-EGFP- $\alpha$ TAT1 ( $\alpha$ TAT1), and WOP-EGFP expressing cells (EGFP) were separated by SDS/PAGE, blotted onto the membrane, and acetylated $\alpha$-tubulin, EGFP, and GAPDH were stained by specific antibodies. (M) Lysates of infected WOP, WOP-EGFP- $\alpha$ TAT1, and WOP-EGFP expressing cells were performed at 40 hpi and resolved by SDS/PAGE; proteins transferred onto the membrane and VP1 and GAPDH were stained by specific antibodies. (N) Graphic illustration of the densitometry analysis of the digital images of Western blots of three independent experiments. Shown is the fold change relative to the WOP cells +/SD. (O) WOP, WOP-EGFP- $\alpha$ TAT1, and WOP-EGFP expressing cells were infected, and $48 \mathrm{hpi} \mathrm{MPyV}$ virions were isolated. 3T6 cells were infected with equal volumes of the isolated virus from cells. Cells were fixed at $24 \mathrm{hpi}$, and the LT antigen was stained by a specific antibody. The values in the graph refer to the fold change in the numbers of LT antigen positive cells relative to WOP cells and represent the mean values of three independent experiments $+/-\mathrm{SD} \times$ indicate non-specific antibody staining. ${ }^{*} p<0.05,{ }^{* *} p<0.01,{ }^{* * *} p<0.001$ determined by the Student's $t$ test, ns-not significant.

\subsection{Acetylated Microtubules Are Not Necessary for Viral Infection}

Finally, we addressed the role of microtubule acetylation in MPyV infection. To determine whether the absence of microtubule acetylation affects MPyV infection, the levels of LT and VP1 proteins and virus production were tested in $\alpha \mathrm{TAT} 1 \mathrm{KO}$ cells. These cells do not express the major tubulin acetyltransferase, tubulin acetyltransferase 1, and lack acetylated microtubules [23]. The absence of acetylated $\alpha$-tubulin in $\alpha$ TAT1 KO cells was confirmed by a Western blot analysis of cell lysates using the antibody specific to acetylated $\alpha$-tubulin (Figure 7A). The levels of LT antigen (relative to GAPDH levels) and VP1 at 40 hpi were only slightly decreased in $\alpha$ TAT1 KO cells compared to their wild-type counterparts (Figure 7B,C). We failed to compare the amounts of virus progeny at $48 \mathrm{hpi}$ in 3T3-wt and $\alpha$ TAT1 KO cells. The problem we encountered was the increased proliferation of $\alpha$ TAT1 KO cells in comparison with the parental cell line. In addition, the altered phosphorylation capacity of $\alpha \mathrm{TAT} 1 \mathrm{KO}$ cells due to deregulation of the Hippo pathway [23] may substantially affect virion production, as virion assembly is positively affected by VP1 phosphorylation [43]. This fact may distort the interpretation of the results.

Furthermore, we artificially elevated the amount of acetylated tubulin by tubacin, a specific inhibitor of HDAC6 [44], and examined the levels of LT antigen, VP1, and viral production at $48 \mathrm{hpi}$. The increase in tubulin acetylation in cells after tubacin treatment was confirmed by a Western blot analysis of cell lysates using an antibody specific to acetylated $\alpha$-tubulin (Figure 7D). The amount of the LT antigen was not significantly affected by tubacin treatment (Figure 7E,F), indicating that elevated levels of tubulin acetylation do not restrict early antigen production. However, the level of VP1 in tubacin treated cells was two times higher compared with that of non-treated cells. Surprisingly, despite the increased level of VP1 in tubacin treated cells, the amount of virion progeny dropped to $67 \%$ in comparison with the virions produced by the mock-treated cells (Figure 7E-G).

Histone deacetylase 6 is a protein with a wide range of actions. In addition to deacetylase activity, it also possesses a ubiquitin binding domain at its $\mathrm{C}$-terminus and thus affects protein metabolism [45]. Moreover, HDAC6 also deacetylates other proteins besides $\alpha$-tubulin, such as chaperones, and influences their functions [46,47]. Therefore, the observed inhibition effect of HDAC6 on VP1 levels and virion production is not necessarily connected with elevated levels of microtubule acetylation but may reflect the inhibition or activation of other HDAC6 functions. To determine this, we tested the impact of HDAC6 inhibition on the amount of the LT antigen, VP1, and virus production in infected $\alpha$ TAT1 KO cells. Since $\alpha$ TAT1 KO cells lack $\alpha$ TAT1, the inhibition of HDAC 6 cannot affect microtubule acetylation. After tubacin treatment, the $\alpha$ TAT1 $\mathrm{KO}$ cells and their wt-counterparts exhibited similar effects to the 3T6 cells in the previous experiment. The amount of LT was not significantly affected by HDAC6 inhibition, whereas the level of VP1 was almost 2.5 or 2 times higher compared to the mock-treated 3T3 or $\alpha \mathrm{TAT} 1 \mathrm{KO}$ cells, respectively (Figure 7H-J). Also, the amount of infectious virus produced by tubacin-treated 3T3 and $\alpha \mathrm{TAT} 1 \mathrm{KO}$ cells dropped to $74 \%$ and $66 \%$, respectively (Figure 7K). These data show that the observed impact of HDAC6 inhibition was not 
a consequence of the elevation of microtubule acetylation but a result of the inhibition of other HDAC6 functions.

To further test the relevance of microtubule acetylation in MPyV infection, the amount of LT antigen, VP1, and viral production was examined in WOP-EGFP- $\alpha$ TAT1 cells overexpressing EGFP- $\alpha$ TAT1. These cells, due to the overexpression of the major tubulin acetyltransferase, exhibited elevated levels of tubulin acetylation. The overexpression of $\alpha \mathrm{TAT} 1$ and elevated level of acetylated $\alpha$-tubulin in WOP-EGFP- $\alpha$ TAT1 cells was confirmed by a Western blot analysis of cell lysates using an antibody specific to EGFP or acetylated $\alpha$-tubulin (Figure 6I, Figure 7L). We showed that increased levels of microtubule acetylation influenced neither VP1 levels nor the production of progeny virions (Figure $7 \mathrm{M}-\mathrm{O}$ ).

Taken together, these data indicate that microtubule hyperacetylation is not essential for MPyV infection. Additionally, the data show that the inhibition of HDAC6 has a significant impact on MPyV infection, but the reasons behind this effect require further examination.

\section{Discussion}

Microtubules are crucial structures within cells. They are absolutely essential for the intracellular transport of organelles, secretory vesicles, and macromolecular complexes. In addition, microtubules are involved in cell division and cell movement; also, they maintain cell structure and cell polarity. In order to perform these diverse functions, cells build microtubule meshes with various morphologies and dynamics. This diversity is generated through the expression of different tubulin isoforms and posttranslational modifications.

The role of the microtubular network in virus infection has been intensively studied and, in the case of many viruses, well characterized [48]. Furthermore, the relevance of the microtubular network in polyomavirus virion entry and trafficking inside the host cells has been well described [49-51]. However, the role of the microtubular network in the late stages of polyomavirus infection and the significance of microtubule posttranslational modifications to infection remain poorly understood.

In this study, we focused on characterizing the relationship of VP1-microtubule interactions, their hyperacetylation and stability, and the functional meaning of elevated microtubule $\alpha$ K40 acetylation during the late phase of MPyV infection. We showed that tubulin $\alpha \mathrm{K} 40$ acetylation increased gradually in the late phase of infection depending on the amount of VP1 in infected cells. Also, in transfected cells expressing VP1, the level of $\alpha \mathrm{K} 40$ tubulin acetylation increased with increasing level of VP1 production [3]. Consequently, VP1 may be involved in the deregulation of microtubule $\alpha \mathrm{K} 40$ acetylation. Although the changes in $\alpha \mathrm{K} 40$ tubulin acetylation during viral infection have been described for many viruses [52] how viral infection affects the $\alpha \mathrm{K} 40$ tubulin acetylation level is still poorly characterized. One way to alter microtubule acetylation is to affect HDAC6. The envelope protein gp120 of human immunodeficiency virus 1 (HIV-1) increased the level of HDAC6 in primary rat neurons [53], while influenza A virus reduced the level of HDAC6 in infected cells [54]. We showed that MPyV infection does not affect the mRNA levels of either HDAC6 or $\alpha$ TAT1. Therefore, we further tested possible stimulation of $\alpha$ TAT1 activity.

According to the model of Coombes et al. [38], $\alpha$ TAT1 stochastically enters the lumen at microtubule ends or through breaks in the lattice. Then, the mobility of $\alpha \mathrm{TAT} 1$ within the lumen is controlled by the affinity of $\alpha$ TAT1 to its binding sites, which are highly concentrated within the lumen [38]. Several conditions may enhance $\alpha$ TAT1 activity: (i) the number of microtubules ends, (ii) the numbers of breaks and openings in the lattice, and (iii) microtubule stability. Despite the slow rate of $\alpha$-tubulin acetylation in the lumens of microtubules, $\alpha \mathrm{TAT} 1$ may be able to slowly but efficiently acetylate stable microtubules while traveling down the lumen [38]. In VP1-positive cells, an increased level of microtubules was observed, and the VP1-mediated stabilization of microtubules was demonstrated, both in vitro and in vivo. The increased number of stable microtubules in cells may provide a substrate for $\alpha$ TAT1 acetylation along the entire length of the microtubules. The proposed model may be enhanced by other processes. We cannot, for example, rule out that VP1 stabilization may lead to 
increased breakage in the microtubule lattice, thus increasing $\alpha \mathrm{TAT} 1$ activity. It was reported that the stabilization of microtubules by taxol led to more open, sheet like microtubule structures [38]. On the contrary, the HIV-1 envelope protein gp120 was shown to interact with tubulin $\beta-3$ to prevent microtubule polymerization, which led to a decrease in microtubule $\alpha$ K40 acetylation [55]. We showed that VP1 interferes with microtubule polymerization in vitro, but the significance of this phenomenon in living cells, as well as its influence on microtubule stabilization, needs to be elucidated.

Alterations of microtubule dynamics, accompanied by $\alpha \mathrm{K} 40$ acetylation changes, have been described as necessary for several viruses. The stabilization of microtubules is involved in virus trafficking in the cell. Entering HIV-1 particles induce microtubule stabilization for efficient translocation through cytoplasm [56]. The infection of adenoviruses or mouse norovirus 1 leads to stable microtubule reorganization $[57,58]$. The VP1 of the mouse polyomavirus binds the microtubules, including the mitotic spindle, which results in blocking the cell cycle in the G2/M phase [3]. The reorganization of microtubules is related to rearrangements of other parts of the cytoskeleton, leading to changes in the mechanical properties of the cells. It has been shown that early $\mathrm{T}$ antigens of polyomaviruses affect the different components of cytoskeleton networks. The constitutive expression of the LT antigen of the Simian virus 40 resulted in a collapse of the vimentin network followed by the down-regulation of microtubule $\alpha \mathrm{K} 40$ acetylation and the re-localization of acetylated microtubules to the center of the cells. These cytoskeletal rearrangements led to an increase in cell stiffness at the cell periphery [59]. Likewise, the small $\mathrm{T}$ antigen of the Merkel cell polyomavirus destabilizes microtubules and increases cell mobility [60]. In the late phase of MPyV infection, VP1-induced microtubule stabilization followed by increased acetylation may compensate for the destabilization effects of early $\mathrm{T}$ antigens to preserve cell shape. Also, the observed blocking of the cell cycle in the G2/M phase and the prolonged S-phase are apparently important factors for completion of the MPyV infection cycle.

The stabilization of microtubules and their acetylation favors motor binding, thus enhancing their movement along the microtubules [53,61]. The disruption of microtubules by nocodazole inhibited the release of MPyV from infected cells [50], suggesting that intact and likely stable microtubules are indispensable for the active release of MPyV progeny from infected cells. Although our experiments indicated that the $\alpha \mathrm{K} 40$ acetylation of microtubules per se is not required for the late phase of MPyV infection, the positive effects of microtubule stabilization and acetylation on the movement of viral components cannot be excluded.

The role of the HDAC6 enzyme in MPyV infection might be more complex. Although we did not observe HDAC6 involvement in microtubule acetylation, our results indicate that HDAC6 is involved in the late phase of MPyV infection. The inhibition of HDAC6 by tubacin resulted in increased levels of VP1 and a decrease in the production of viral progeny. Besides $\alpha$-tubulin, HDAC6 also interacts with other substrates, including chaperones [47]. Moreover, apart from its deacetylation activity, HDAC6 binds ubiquitinylated proteins $[45,62]$ and thus plays a crucial role in protein metabolism [63].

HDAC6 may regulate the MPyV lifecycle indirectly via its substrates, especially chaperones. HDAC6 is responsible for Hsp90 activity, as the hyperacetylation of Hsp90 results in the unsatisfactory binding of client proteins $[46,64]$. It was demonstrated that the polymerase of the Japanese encephalitis virus needs to be stabilized by Hsp90. The inhibition of HDAC6 leads to Hsp90 hyperacetylation, polymerase destabilization, and decreases viral replication [65]. Chaperones are involved in the MPyV life cycle, so their activity maintenance by HDAC6 may be important for viral propagation. Moreover, the VP1 protein is acetylated [66] and also ubiquitinylated (our unpublished data). Thus, VP1 can serve as a substrate for HDAC6. HDAC6 may participate in the late phase of infection in various ways. It may directly regulate the metabolism of MPyV structural proteins and the viral assembly. Indirectly, it can affect chaperone activation. Further research is required to characterize the function of HDAC6 in the polyomavirus life cycle and reveal whether HDAC6 is a promising target for the antiviral therapy of diseases associated with polyomaviruses.

Supplementary Materials: The following are available online at http://www.mdpi.com/1999-4915/12/2/227/s1, Figure S1: Characterization of VP1/EGFP-tVP3 virus-like particles and capsomeres. 
Author Contributions: Conceptualization, L.H. and J.F.; validation, L.H., K.B., I.Z., and J.F.; formal analysis, L.H and IZ; investigation, L.H., K.B., B.R., I.Z., M.F., and Z.M.; writing-original draft preparation, L.H., I.Z., and J.F.; writing-review and editing, L.H., J.F., and Z.L.; visualization, L.H., K.B., I.Z., B.R., and M.F.; supervision, J.F.; project administration, J.F.; funding acquisition, J.F., I.Z., and Z.L. All authors have read and agreed to the published version of the manuscript.

Funding: This research was funded by the Grant Agency of the Czech Republic, project 16-07977S (LH, BR, MF, JF), by the League Against Cancer Prague (LH), by the Ministry of Education, Youth and Sports from the targeted support scheme of the National Sustainability Program, project LQ1604 (KB), by the Grant Agency of Charles University (project no. 1372218) (IZ) and the institutional support from the CAS (RVO: 86652036) (IZ, ZL). We acknowledge the Imaging Methods Core Facility at BIOCEV, an institution supported by the Czech-BioImaging large RI projects (LM2015062 and CZ.02.1.01/0.0/0.0/16_013/0001775, funded by MEYS CR) for their support in obtaining imaging data presented in this paper.

Acknowledgments: We are grateful to Christopher Buck for providing valuable plasmids and to Maxence V. Nachury for the kind gift of valuable plasmids and cell lines. We thank Yulia Bobrova for technical support.

Conflicts of Interest: The authors declare no conflict of interest.

\section{References}

1. Barouch, D.H.; Harrison, S.C. Interactions among the major and minor coat proteins of polyomavirus. J. Virol. 1994, 68, 3982-3989. [CrossRef] [PubMed]

2. Soldatova, I.; Prilepskaja, T.; Abrahamyan, L.; Forstová, J.; Huerfano, S. Interaction of the Mouse Polyomavirus Capsid Proteins with Importins Is Required for Efficient Import of Viral DNA into the Cell Nucleus. Viruses 2018, 10, 165. [CrossRef] [PubMed]

3. Horníková, L.; Fraiberk, M.; Man, P.; Janovec, V.; Forstová, J. VP 1, the major capsid protein of the mouse polyomavirus, binds microtubules, promotes their acetylation and blocks the host cell cycle. FEBS J. 2017, 284, 301-323. [CrossRef] [PubMed]

4. Salunke, D.M.; Caspar, D.L.; Garcea, R.L. Self-assembly of purified polyomavirus capsid protein VP1. Cell 1986, 46, 895-904. [CrossRef]

5. O'Hara, S.D.; Stehle, T.; Garcea, R.L. Glycan receptors of the Polyomaviridae: Structure, function, and pathogenesis. Curr. Opin. Virol. 2014, 7, 73-78. [CrossRef]

6. Bird, G.; O’Donnell, M.; Moroianu, J.; Garcea, R.L. Possible Role for Cellular Karyopherins in Regulating Polyomavirus and Papillomavirus Capsid Assembly. J. Virol. 2008, 82, 9848-9857. [CrossRef]

7. Palková, Z.; Španielová, H.; Gottifredi, V.; Hollanderová, D.; Forstová, J.; Amati, P. The polyomavirus major capsid protein VP1 interacts with the nuclear matrix regulatory protein YY1. FEBS Lett. 2000, 467, 359-364. [CrossRef]

8. Carbone, M.; Reale, A.; Di Sauro, A.; Sthandier, O.; Garcia, M.-I.; Maione, R.; Caiafa, P.; Amati, P. PARP-1 Interaction with VP1 Capsid Protein Regulates Polyomavirus Early Gene Expression. J. Mol. Boil. 2006, 363, 773-785. [CrossRef]

9. Garcia, M.-I.; Perez, M.; Caruso, M.; Sthandier, O.; Ferreira, R.; Cermola, M.; Macchia, C.; Amati, P. A Mutation in the DE Loop of the VP1 Protein That Prevents Polyomavirus Transcription and Replication. Virology 2000, 272, 293-301. [CrossRef]

10. Chromy, L.R.; Pipas, J.M.; Garcea, R.L. Chaperone-mediated in vitro assembly of Polyomavirus capsids. Proc. Natl. Acad. Sci. USA 2003, 100, 10477-10482. [CrossRef]

11. Soppina, V.; Herbstman, J.F.; Skiniotis, G.; Verhey, K.J. Luminal Localization of $\alpha$-tubulin K40 Acetylation by Cryo-EM Analysis of Fab-Labeled Microtubules. PLoS ONE 2012, 7, e48204. [CrossRef] [PubMed]

12. Xu, Z.; Schaedel, L.; Portran, D.; Aguilar, A.; Gaillard, J.; Marinkovich, M.P.; Thery, M.; Nachury, M.V. Microtubules acquire resistance from mechanical breakage through intralumenal acetylation. Science 2017, 356, 328-332. [CrossRef] [PubMed]

13. Portran, D.; Schaedel, L.; Xu, Z.; Théry, M.; Nachury, M.V. Tubulin acetylation protects long-lived microtubules against mechanical ageing. Nat. Cell Biol. 2017, 19, 391-398. [CrossRef] [PubMed]

14. Eshun-Wilson, L.; Zhang, R.; Portran, D.; Nachury, M.V.; Toso, D.B.; Löhr, T.; Vendruscolo, M.; Bonomi, M.; Fraser, J.S.; Nogales, E. Effects of $\alpha$-tubulin acetylation on microtubule structure and stability. Proc. Natl. Acad. Sci. USA 2019, 116, 10366-10371. [CrossRef] [PubMed]

15. Akella, J.S.; Wloga, D.; Kim, J.; Starostina, N.G.; Lyons-Abbott, S.; Morrissette, N.S.; Dougan, S.T.; Kipreos, E.T.; Gaertig, J. MEC-17 is an alpha-tubulin acetyltransferase. Nature 2010, 467, 218-222. [CrossRef] [PubMed] 
16. Kalebic, N.; Sorrentino, S.; Perlas, E.; Bolasco, G.; Martinez, C.; Heppenstall, P.A. $\alpha$ TAT1 is the major $\alpha$-tubulin acetyltransferase in mice. Nat. Commun. 2013, 4, 1962. [CrossRef]

17. Shida, T.; Cueva, J.G.; Xu, Z.; Goodman, M.B.; Nachury, M.V. The major alpha-tubulin K40 acetyltransferase alphaTAT1 promotes rapid ciliogenesis and efficient mechanosensation. Proc. Natl. Acad. Sci. USA 2010, 107, 21517-21522. [CrossRef]

18. Hubbert, C.; Guardiola, A.; Shao, R.; Kawaguchi, Y.; Ito, A.; Nixon, A.; Yoshida, M.; Wang, X.-F.; Yao, T.-P. HDAC6 is a microtubule-associated deacetylase. Nature 2002, 417, 455-458. [CrossRef]

19. Miyake, Y.; Keusch, J.J.; Wang, L.; Saito, M.; Hess, D.; Wang, X.; Melancon, B.J.; Helquist, P.; Gut, H.; Matthias, P. Structural insights into HDAC6 tubulin deacetylation and its selective inhibition. Nat. Methods 2016, 12, 748-754. [CrossRef]

20. Chen, L.; Fluck, M.M. Kinetic Analysis of the Steps of the Polyomavirus Lytic Cycle. J. Virol. 2001, 75, 8368-8379. [CrossRef]

21. Dahl, J.; You, J.; Benjamin, T. Induction and Utilization of an ATM Signaling Pathway by Polyomavirus. J. Virol. 2005, 79, 13007-13017. [CrossRef] [PubMed]

22. Dailey, L.; Basilico, C. Sequences in the polyomavirus DNA regulatory region involved in viral DNA replication and early gene expression. J. Virol. 1985, 54, 739-749. [CrossRef] [PubMed]

23. Aguilar, A.; Becker, L.; Tedeschi, T.; Heller, S.; Iomini, C.; Nachury, M.V. $\alpha$-Tubulin K40 acetylation is required for contact inhibition of proliferation and cell-substrate adhesion. Mol. Boil. Cell 2014, 25, 1854-1866. [CrossRef] [PubMed]

24. Horníková, L.; Zila, V.; Španielová, H.; Forstová, J. Mouse Polyomavirus: Propagation, Purification, Quantification, and Storage. Curr. Protoc. Microbiol. 2015, 38. [CrossRef]

25. Boura, E.; Liebl, D.; Špíšek, R.; Fric, J.; Marek, M.; Štokrová, J.; Holan, V.; Forstová, J. Polyomavirus EGFP-pseudocapsids: Analysis of model particles for introduction of proteins and peptides into mammalian cells. FEBS Lett. 2005, 579, 6549-6558. [CrossRef] [PubMed]

26. Tolstov, Y.L.; Pastrana, D.V.; Feng, H.; Becker, J.C.; Jenkins, F.J.; Moschos, S.; Chang, Y.; Buck, C.B.; Moore, P.S. Human Merkel cell polyomavirus infection II. MCV is a common human infection that can be detected by conformational capsid epitope immunoassays. Int. J. Cancer 2009, 125, 1250-1256. [CrossRef]

27. Horníková, L.; Man, P.; Forstová, J. Blue native protein electrophoresis for studies of mouse polyomavirus morphogenesis and interactions between the major capsid protein VP1 and cellular proteins. J. Virol. Methods 2011, 178, 229-234. [CrossRef]

28. Forstová, J.; Krauzewicz, N.; Wallace, S.; Street, A.J.; Dilworth, S.M.; Beard, S.; Griffin, E.B. Cooperation of structural proteins during late events in the life cycle of polyomavirus. J. Virol. 1993, 67, 1405-1413. [CrossRef]

29. Dilworth, S.M.; Griffin, B.E. Monoclonal antibodies against polyoma virus tumor antigens. Proc. Natl. Acad. Sci. USA 1982, 79, 1059-1063. [CrossRef]

30. Staufenbiel, M.; Deppert, W. Preparation of nuclear matrices from cultured cells: Subfractionation of nuclei in situ. J. Cell Boil. 1984, 98, 1886-1894. [CrossRef]

31. Sennepin, A.D.; Charpentier, S.; Normand, T.; Sarré, C.; Legrand, A.; Mollet, L.M. Multiple reprobing of Western blots after inactivation of peroxidase activity by its substrate, hydrogen peroxide. Anal. Biochem. 2009, 393, 129-131. [CrossRef] [PubMed]

32. Minotti, A.M.; Barlow, S.B.; Cabral, F. Resistance to antimitotic drugs in Chinese hamster ovary cells correlates with changes in the level of polymerized tubulin. J. Boil. Chem. 1991, 266, 3987-3994.

33. Gell, C.; Friel, C.T.; Borgonovo, B.; Drechsel, D.N.; Hyman, A.A.; Howard, J. Purification of Tubulin from Porcine Brain. Adv. Struct. Saf. Stud. 2011, 777, 15-28.

34. Castoldi, M.; Popov, A.V. Purification of brain tubulin through two cycles of polymerization-depolymerization in a high-molarity buffer. Protein Expr. Purif. 2003, 32, 83-88. [CrossRef]

35. Hyman, A.; Drechsel, D.; Kellogg, U.; Salser, S.; Sawin, K.; Steffen, P.; Wordeman, L.; Mitchison, T. Preparation of modified tubulins. Methods Enzym. 1991, 196, 478-485.

36. Nitzsche, B.; Bormuth, V.; Bräuer, C.; Howard, J.; Ionov, L.; Kerssemakers, J.; Korten, T.; LeDuc, C.; Ruhnow, F.; Diez, S. Studying Kinesin Motors by Optical 3D-Nanometry in Gliding Motility Assays. Methods Cell Biol. 2010, 95, 247-271.

37. Braun, M.; Lansky, Z.; Fink, G.; Ruhnow, F.; Diez, S.; Janson, M.E. Adaptive braking by Ase1 prevents overlapping microtubules from sliding completely apart. Nature 2011, 13, 1259-1264. [CrossRef] 
38. Coombes, C.; Yamamoto, A.; McClellan, M.; Reid, T.A.; Plooster, M.; Luxton, G.G.; Alper, J.; Howard, J.; Gardner, M.K. Mechanism of microtubule lumen entry for the $\alpha$-tubulin acetyltransferase enzyme $\alpha$ TAT1. Proc. Natl. Acad. Sci. USA 2016, 113, E7176-E7184. [CrossRef]

39. Lin, W.; Hata, T.; Kasamatsu, H. Subcellular distribution of viral structural proteins during simian virus 40 infection. J. Virol. 1984, 50, 363-371. [CrossRef]

40. Erickson, K.D.; Bouchet-Marquis, C.; Heiser, K.; Szomolanyi-Tsuda, E.; Mishra, R.; Lamothe, B.; Hoenger, A.; Garcea, R.L. Virion Assembly Factories in the Nucleus of Polyomavirus-Infected Cells. PLOS Pathog. 2012, 8. [CrossRef]

41. Montross, L.; Watkins, S.; Moreland, R.B.; Mamon, H.; Caspar, D.L.; Garcea, R.L. Nuclear assembly of polyomavirus capsids in insect cells expressing the major capsid protein VP1. J. Virol. 1991, 65, 4991-4998. [CrossRef] [PubMed]

42. Zhernov, I. Results Show That EGFP Does Not Bind to Microtubules; Institute of Biotechnology of the Czech Academy of Sciences, BIOCEV, Vestec, Czech Republic; Faculty of Mathematics and Physics, Charles University: Prague, Czech Republic, 2020.

43. Garcea, R.L.; Ballmer-Hofer, K.; Benjamin, T.L. Virion assembly defect of polyomavirus hr-t mutants: Underphosphorylation of major capsid protein VP1 before viral DNA encapsidation. J. Virol. 1985, 54, 311-316. [CrossRef] [PubMed]

44. Haggarty, S.J.; Koeller, K.M.; Wong, J.C.; Grozinger, C.M.; Schreiber, S.L. Domain-selective small-molecule inhibitor of histone deacetylase 6 (HDAC6)-mediated tubulin deacetylation. Proc. Natl. Acad. Sci. USA 2003, 100, 4389-4394. [CrossRef]

45. Seigneurin-Berny, D.; Verdel, A.; Curtet, S.; Lemercier, C.; Garin, J.; Rousseaux, S.; Khochbin, S. Identification of Components of the Murine Histone Deacetylase 6 Complex: Link between Acetylation and Ubiquitination Signaling Pathways. Mol. Cell. Boil. 2001, 21, 8035-8044. [CrossRef] [PubMed]

46. Kovacs, J.J.; Murphy, P.J.; Gaillard, S.; Zhao, X.; Wu, J.-T.; Nicchitta, C.V.; Yoshida, M.; Toft, D.O.; Pratt, W.B.; Yao, T.-P. HDAC6 Regulates Hsp90 Acetylation and Chaperone-Dependent Activation of Glucocorticoid Receptor. Mol. Cell 2005, 18, 601-607. [CrossRef] [PubMed]

47. Zhang, L.; Liu, S.; Liu, N.; Zhang, Y.; Liu, M.; Li, D.; Seto, E.; Yao, T.-P.; Shui, W.; Zhou, J. Proteomic identification and functional characterization of MYH9, Hsc70, and DNAJA1 as novel substrates of HDAC6 deacetylase activity. Protein Cell 2015, 6, 42-54. [CrossRef]

48. Naghavi, M.H.; Walsh, D. Microtubule Regulation and Function during Virus Infection. J. Virol. $2017,91$. [CrossRef]

49. Zila, V.; Difato, F.; Klimova, L.; Huerfano, S.; Forstová, J. Involvement of Microtubular Network and Its Motors in Productive Endocytic Trafficking of Mouse Polyomavirus. PLoS ONE 2014, 9. [CrossRef]

50. Sanjuan, N.; Porrás, A.; Otero, J. Microtubule-dependent intracellular transport of murine polyomavirus. Virology 2003, 313, 105-116. [CrossRef]

51. Eash, S.; Atwood, W.J. Involvement of Cytoskeletal Components in BK Virus Infectious Entry. J. Virol. 2005, 79, 11734-11741. [CrossRef]

52. Zheng, K.; Jiang, Y.; He, Z.; Kitazato, K.; Wang, Y. Cellular defence or viral assist: The dilemma of HDAC6. J. Gen. Virol. 2017, 98, 322-337. [CrossRef] [PubMed]

53. Wenzel, E.D.; Speidell, A.; Flowers, S.A.; Wu, C.; Avdoshina, V.; Mocchetti, I. Histone deacetylase 6 inhibition rescues axonal transport impairments and prevents the neurotoxicity of HIV-1 envelope protein gp120. Cell Death Dis. 2019, 10, 1-15. [CrossRef] [PubMed]

54. Husain, M.; Harrod, K. Influenza A virus-induced caspase-3 cleaves the histone deacetylase 6 in infected epithelial cells. FEBS Lett. 2009, 583, 2517-2520. [CrossRef] [PubMed]

55. Avdoshina, V.; Caragher, S.; Wenzel, E.D.; Taraballi, F.; Mocchetti, I.; Harry, G.J. The viral protein gp120 decreases the acetylation of neuronal tubulin: Potential mechanism of neurotoxicity. J. Neurochem. 2017, 141, 606-613. [CrossRef]

56. Sabo, Y.; Walsh, D.; Barry, D.S.; Tinaztepe, S.; Santos, K.D.L.; Goff, S.P.; Gundersen, G.G.; Naghavi, M.H. HIV-1 induces the formation of stable microtubules to enhance early infection. Cell Host Microbe 2013, 14, 535-546. [CrossRef]

57. Warren, J.C.; Rutkowski, A.; Cassimeris, L. Infection with Replication-deficient Adenovirus Induces Changes in the Dynamic Instability of Host Cell Microtubules. Mol. Boil. Cell 2006, 17, 3557-3568. [CrossRef] 
58. Hyde, J.L.; Gillespie, L.K.; MacKenzie, J. Mouse Norovirus 1 Utilizes the Cytoskeleton Network To Establish Localization of the Replication Complex Proximal to the Microtubule Organizing Center. J. Virol. 2012, 86, 4110-4122. [CrossRef]

59. Rathje, L.-S.Z.; Nordgren, N.; Pettersson, T.; Rönnlund, D.; Widengren, J.; Aspenström, P.; Gad, A. Oncogenes induce a vimentin filament collapse mediated by HDAC6 that is linked to cell stiffness. Proc. Natl. Acad. Sci. USA 2014, 111, 1515-1520. [CrossRef]

60. Knight, L.M.; Stakaityte, G.; Wood, J.J.; Abdul-Sada, H.; Griffiths, D.A.; Howell, G.J.; Wheat, R.; Blair, G.E.; Steven, N.M.; Macdonald, A.; et al. Merkel cell polyomavirus small T antigen mediates microtubule destabilization to promote cell motility and migration. J. Virol. 2015, 89, 35-47. [CrossRef]

61. Dompierre, J.P.; Godin, J.D.; Charrin, B.C.; Cordelières, F.P.; King, S.J.; Humbert, S.; Saudou, F. Histone deacetylase 6 inhibition compensates for the transport deficit in Huntington's disease by increasing tubulin acetylation. J. Neurosci. 2007, 27, 3571-3583. [CrossRef]

62. Boyault, C.; Gilquin, B.; Zhang, Y.; Rybin, V.; Garman, E.F.; Meyer-Klaucke, W.; Matthias, P.; Müller, C.W.; Khochbin, S. HDAC6-p97/VCP controlled polyubiquitin chain turnover. EMBO J. 2006, 25, 3357-3366. [CrossRef] [PubMed]

63. Li, Y.; Shin, D.; Kwon, S.H. Histone deacetylase 6 plays a role as a distinct regulator of diverse cellular processes. FEBS J. 2013, 280, 775-793. [CrossRef] [PubMed]

64. Fiskus, W.; Ren, Y.; Mohapatra, A.; Bali, P.; Mandawat, A.; Rao, R.; Herger, B.; Yang, Y.; Atadja, P.; Wu, J.; et al. Hydroxamic acid analogue histone deacetylase inhibitors attenuate estrogen receptor-alpha levels and transcriptional activity: A result of hyperacetylation and inhibition of chaperone function of heat shock protein 90. Clin. Cancer Res. 2007, 13, 4882-4890. [CrossRef] [PubMed]

65. Lu, C.-Y.; Chang, Y.-C.; Hua, C.-H.; Chuang, C.; Huang, S.-H.; Kung, S.-H.; Hour, M.-J.; Lin, C.-W. Tubacin, an HDAC6 Selective Inhibitor, Reduces the Replication of the Japanese Encephalitis Virus via the Decrease of Viral RNA Synthesis. Int. J. Mol. Sci. 2017, 18, 954. [CrossRef]

66. Bolen, J.B.; Anders, D.G.; Trempy, J.; Consigli, A.R. Differences in the subpopulations of the structural proteins of polyoma virions and capsids: Biological functions of the multiple VP1 species. J. Virol. 1981, 37, 80-91. [CrossRef]

(C) 2020 by the authors. Licensee MDPI, Basel, Switzerland. This article is an open access article distributed under the terms and conditions of the Creative Commons Attribution (CC BY) license (http://creativecommons.org/licenses/by/4.0/). 